\title{
Foldamers Based on Remote Intrastrand Interactions
}

Philippe Le Grel and Gilles Guichard

\section{1}

Introduction

In just a decade, the field of foldamers has gained respectability. The early contributions of Gellman [1, 2] and Seebach [3, 4] with foldamers based on remote intrastrand interactions have undoubtedly played a large part in the current dynamism of this rapidly evolving field. In the mid-1990s, both groups demonstrated that designed short-chain homo-oligomers made of unnatural units ( $\beta$-amino acids) could self-organize in a controlled fashion to form defined secondary structures (e.g. helices, sheets and $\beta$-hairpins) reminiscent of those of $\alpha$-polypeptides. To a large extent, unnatural backbones with folding propensity reported in this chapter are "proteinomimetics". In principle, intrastrand interactions in designed oligomers may result from a variety of noncovalent forces including steric repulsion, H-bonds, electrostatic and aromatic-aromatic interactions, coordination to metal ions, as well as solvophobic effects (see also Chapters 3 and 4). H-bonds play an important role in foldamer design, in part because they are robust and directional. H-bonding certainly provides the most versatile way to create intrastrand connections that are useful to stabilize intrinsically flexible oligomeric chains into ordered structures. In this context, the amide linkage has regularly appeared as a motif to elaborate oligomeric strands that self-organize through H-bonding. In recent years, nonpeptide backbones, hetereogeneous (hybrid) oligoamide backbones composed of multiple residue types as well as abiotic aromatic oligoamides have emerged as new classes of folded oligomers. These systems, whose propensity for folding is also controlled by noncovalent interactions between non-nearest neighbors, are surveyed in this chapter. The main challenges lie in the ways to control backbone pre-organization, to develop robust predictable secondary motifs and to integrate multiple levels of complexity to create unprecedented folded shapes. Recent studies have highlighted the strength and usefulness of theoretical studies to explore possible secondary structure ensembles in aliphatic oligoamides of various complexities (see also Chapter 6). In a number of systems based on remote intrastrand interactions, the predictability 
of folding can now be integrated to develop molecules with function. Successful applications of these foldamers in biology are further discussed in Chapter 8.

\section{2}

\section{What can be Learned from Strategies used to Control Conformations of $\alpha$-Polypeptides?}

Remarkable progress has been achieved over the last 20 years in understanding the factors that govern folding of linear $\alpha$-polypeptide strands into well-ordered and compact secondary structures, as well as in the de novo design of individual protein secondary structure elements and protein folds from $\alpha$-polypeptides (see also Chapter 4) [5-10]. The principles that guided the design of well-folded $\alpha$ polypeptides have been an invaluable source of inspiration to those in the field of foldamers based on remote H-bonding interactions.

Formation of stable and regular secondary structures maintained by intramolecular H-bonds (e.g. helices) requires pre-organization of the main chain so that sequentially remote $\mathrm{H}$-bond donor and acceptors can be positioned in close spatial vicinity, and optimal H-bonding can occur without significant conformational alteration [11]; (in $\alpha$-polypeptides, the preferred backbone conformation derives in part from minimization of Newman and Pitzer strain, as well as pseudo-allylic a $(1,3)$ strain, which restricts the $\phi$ and $\psi$ torsion angle values accessible to proteinogenic amino acid residues). A number of approaches have been developed to reinforce the stability of $\alpha$-peptide folds. Proteinogenic $\alpha$-amino acids have intrinsic and distinct propensities for helices and sheets and can be selected accordingly to stabilize a given fold [12-14]. For example, in the case of noncharged residues, Ala and Leu are strong helix inducers compared with $\beta$-branched Val which instead has an intrinsic propensity to stabilize sheet structures. A higher degree of stabilization can be achieved by restricting further the available conformational space of amino acids in the sequence [5]. This approach has been instrumental in the successful design of foldamers based on remote intrastrand interactions (see following sections). In $\alpha$-peptides, Thorpe-Ingold effects $(\mathrm{C}(\alpha)$-tetrasubstitution) have been used extensively to impose such a restriction on $\phi$ and $\psi$ angles [15]. Aib ( $\alpha$-aminoisobutyric acid), the archetype of achiral $\alpha, \alpha$-dialkylated residue with $(\phi, \psi)$ values around $\left(+60^{\circ},+30^{\circ}\right)$ and $\left(-60^{\circ},-30^{\circ}\right)$ is a remarkably strong promoter of helical ( $3_{10}$ and $\alpha$-helices) and $\beta$-turn (type III/III' and type I/I') structures $[5,10]$.

The $\alpha$-helix is polarized from $\mathrm{N}$ to $\mathrm{C}$ terminus. Hence, its stability can be enhanced by suppressing repulsive electrostatic interactions between the terminal charges and the helix dipole, using appropriate capping groups [12, 16]. Conversely, favorable charge-dipole interactions can be introduced by positioning residues with appropriately charged side chains close to the $N$ and $C$ termini [12]. The creation of ion pairs or salt bridges between oppositely charged side chains of amino acids separated by one helical turn ( $i$ and $i+4$ positions) has been successfully applied to stabilize $\alpha$-helical secondary structures [17]. Other helix stabi- 
lizing $i / i+4$ side-chain to side-chain interactions include hydrophobic interactions [12] and polar interactions with aromatic side chains $[18,19]$. The spatial proximity of residues in a $i / i+4$ relationship within the $\alpha$-helical backbone also offers the possibility of constructing various types of helix-stabilizing macrocycles closed by metal [20, 21], disulfide [22], lactam [23] or olefinic [24, 25] bridges.

\section{3}

Helices from Homogeneous Oligomeric Backbones with Periodicity at the Monomer Level: $\omega$-Peptides and their Analogs

Helices (single-stranded and multi-stranded) represent a major structural motif in biological macromolecules and are interesting scaffolds for displaying appendages in a controlled direction within the 3-D space. Aliphatic oligoamides built from enantiopure $\beta$ - or $\gamma$-amino acid residues, namely $\beta$ - and $\gamma$-peptides are the archetypal helix-forming foldamers. The conformational preference of these homogeneous backbones in solution and in the solid state has been extensively studied and reviewed in detail [2, 4, 26-35]. Five helical shapes differing by the size and orientation of their $\mathrm{H}$-bonded ring have been identified in $\beta$-peptides depending upon residue substitution pattern and stereochemistry, thus illustrating the remarkable structural diversity of these synthetic oligomers: namely 14-, 12(Section 2.3.1), 10- (H-bonding scheme between two consecutive units, mentioned in Section 2.3.1), 8- (Section 2.3.2) and mixed 12/10-helices (see Section 2.4). Noteworthy, the first hint that a polypeptide chain composed of $\beta$ - or $\gamma$-amino acid residues could adopt a regular helical fold structure came from studies of $\beta$ and $\gamma$-amino acid homopolymers some 40 years ago $[36,37]$. It is worth mentioning that a substantial increase in the number of unnatural backbones with propensity to form regular helices came from exploration of the $\beta$ - and $\gamma$-peptide lineages (i.e. $\beta$ - and $\gamma$-peptide mimetics).

\subsection{1}

\section{Compact Helices with Large ( $>10$ atoms) H-bonded Rings}

\subsubsection{The Homologation Strategy: $\boldsymbol{\beta}$ - and $\boldsymbol{\gamma}$-Peptide Foldamers}

Selecting (designing) the right monomeric units to build homo-oligomers that will ultimately show high (helical) folding propensity is obviously a critical and limiting step in the foldamer arena. The choice of $\beta$-amino acids and corresponding $\beta$-peptides by Seebach [3] and Gellman [1] was not pure serendipity. It was initially guided (for Seebach) by the resemblance of the $\beta$-peptide backbone to $\operatorname{poly}((\mathrm{R})-3$-hydroxybutanoic acid) a biopolymer for which a right-handed helical conformation with about three units per turn had been proposed [39, 40], and (for Gellman) by the absence of $\mathrm{H}$-bonding between nearest neighbor amide groups in model $\beta$-homoglycine ( $\beta$-HGly) derivatives [41], a criterion used to evaluate the propensity of the $\beta$-peptide backbone to stabilize folds maintained by $\mathrm{H}$ bonds between sequentially remote amide groups. 
A<smiles>[R]C(=O)C(=O)NC(C)C(=O)NCC</smiles>

$\alpha$-peptide<smiles>[AlH2]</smiles>

$\alpha$-helix $\left[(P)-3.6_{13}\right]$ or $3_{10}$-helix

B

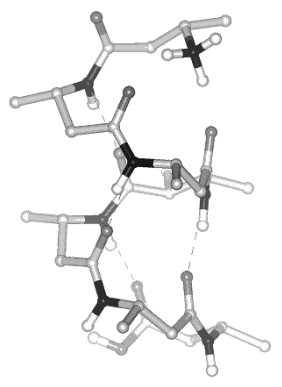

C

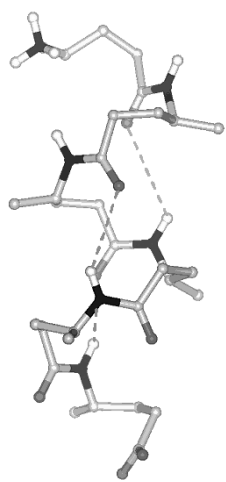

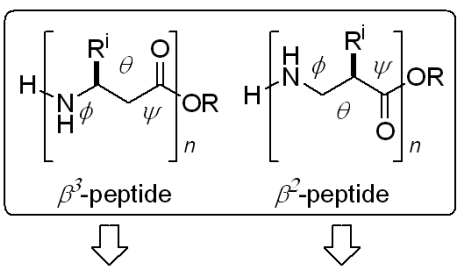

14-helix $\left[(M)-3_{14}\right] \quad$ 14-helix $\left[(P)-3_{14}\right]$

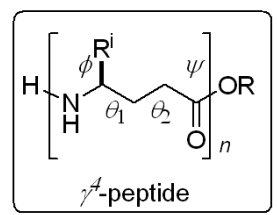

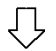

14-helix $\left[(P)-2.6_{14}\right]$
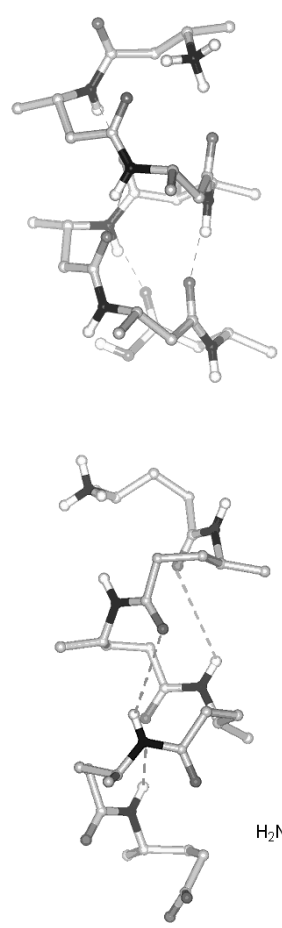

Fig. 2.1 The homologation approach to aliphatic oligoamide foldamers. (A) Peptide foldamers consisting of homologated $\alpha$ amino acids generated by insertion of one $\left(\rightarrow \beta^{2}\right.$ and $\beta^{3}$-peptides) or two $\left(\rightarrow \gamma^{4}\right.$. peptides) $\mathrm{CH}_{2}$ groups, the amino acid side chain remaining unchanged. According to the nomenclature proposed by Balaram [49], the conformational space of $\beta$ - and $\gamma$-peptides can be described by the following sets of backbone torsion angles: $(\omega, \phi, \theta, \psi)$ and $\left(\omega, \phi, \theta_{1}, \theta_{2}, \psi\right)$, respectively. (B) The $\beta$ peptide $3_{14}$ helical fold. Stereo view along the helix axis and top view of the $(M)-314$-helix formed by $\beta^{3}$-peptide 1 determined by NMR in $\mathrm{CD}_{3} \mathrm{OH}$ (adapted from $\left.[43,44]\right)$. Average $(\phi, \theta, \psi)$ values are $\left(-119^{\circ},+63^{\circ},-147^{\circ}\right)$. Side chains have been omitted for clarity. (C) The $\gamma$-peptide $2.6_{14}$ helical fold. Stereo view along the helix axis and top view of a (P)-2.6 14 -helical low energy conformer of 2 (from NMR data in pyridine- $d_{5}$ ). Average $\left(\phi, \theta_{1}, \theta_{2}, \psi\right)$, values calculated on residues $2-5$ are $\left(-127^{\circ},+66^{\circ},+64^{\circ},-140^{\circ}\right)$. Side chains have been partially omitted for clarity (adapted from [45]). 
Detailed NMR conformational analysis of $\beta$-peptides consisting of homologated $\alpha$-amino acids generated by insertion of one $\mathrm{CH}_{2}$ group, the amino acid side chain remaining unchanged, revealed a stable $\left(\beta^{3} \rightarrow \beta^{2}\right.$-peptides) helical fold ( $31_{14^{-}}$or 14-helix) stabilized by 14-membered rings with $\mathrm{H}$-bonds in a forward orientation $\left(1 \rightarrow 3 \mathrm{H}\right.$-bonds between $\mathrm{NH}_{i}$ and $\left.\mathrm{C}=\mathrm{O}_{i+2}\right)$ (e.g. 1, [3, 42-44] Fig. 2.1).

Examination of the top view of the helix indicates that the side chains of residues $i$ and $i+3$ are located nearly on top of each other and suggests that hydrophobic interactions between overlapping aliphatic side chains could play a significant role in stabilizing the overall structure. The distance between facing $\mathrm{C}(\alpha)$ atoms at positions $i$ and $i+3$ is approximately $4.8 \AA$. The helix is compact with a diameter of ca. $4.8 \AA$ slightly larger than that of the $\alpha$-helix $(4.2 \AA)$. Although less studied, their homologs with one additional methylene group inserted in the backbone of each residue, namely the $\gamma$-peptides, have also been found to form stable helical secondary structures in solution [45-48]. $\gamma^{4}$-Peptide chains (e.g. 2) adopt a $2.6_{14}$ helical structure stabilized by $1 \leftarrow 4 \mathrm{H}$ bonds between $\mathrm{C}=\mathrm{O}_{i}$ and $\mathrm{NH}_{i+3}$ closing 14-membered pseudocycles [45]. While the $\alpha$-helix of L- $\alpha$-peptides and the $3_{14}$ helix of the corresponding $\beta^{3}$-peptides have opposite polarity and helicity, the insertion of two $\mathrm{CH}_{2}$ groups in the backbone of $\mathrm{L}-\alpha$-amino acids leaves these two helix parameters unchanged, both the $\alpha$-helix and the 2.6 $6_{14}$ helix of the resulting $\gamma^{4}$-peptides being right-handed and polarized from $\mathrm{N}$ to $\mathrm{C}$ terminus. Both $(M)-3{ }_{14}$ and $(P)-2.6_{14}$ helical backbones are characterized by a $(+)$-synclinal arrangement (gauche conformation) around ethane bonds (e.g. in 1 and 2, $\theta, \theta_{1}$ and $\theta_{2}$ values are $\sim+60^{\circ}\left( \pm 15^{\circ}\right)$ (see Fig. 2.1 for definitions of torsion angles [49]).

Besides NMR and X-ray diffraction (see Section 2.3.1.2), circular dichroism (CD) spectroscopy has been instrumental in studying parameters that influence the formation and stability of the $\beta$-peptide 14-helix. Typically, 14-helical $\beta$ peptides composed of acyclic amino acid residues display a common CD signature with one extremum at $215 \mathrm{~nm}$ (negative for $(M)$-helices and positive for $(P)$ helices) and the other extremum of opposite sign at $195 \mathrm{~nm}$. In sharp contrast to $\alpha$ - and $\beta$-peptides, CD spectra of $\gamma$-peptides were not very informative. $\gamma^{4}$-Peptides such as 2 which populate the 2.6 $6_{14}$ helical fold in solution do not display any characteristic CD signature in $\mathrm{MeOH}$.

\subsubsection{Imposing Backbone Conformational Restriction/Pre-organization for Optimal Helical Folding}

Substantial stabilization of both the $\beta$ - and $\gamma$-peptide 14-helical fold has been achieved by increasing the level of pre-organization of $\beta$ - and $\gamma$-amino acid constituents. However, the rules formulated for $\alpha$-peptides (see Section 2.2) do not necessarily apply (e.g. $\mathrm{C}(\alpha)$ - (or $\mathrm{C}(\beta)$-) tetrasubstitution of $\beta$-amino acid residues is not compatible with $\beta$-peptide 14-helix formation [43, 50-54]) and must be transposed. In particular, it has been shown that acyclic $\beta^{2,3}$-amino acids of like configuration are more effective than their $\beta^{3}$-counterparts in promoting requisite synclinal arrangement around $\mathrm{C}(\alpha)-\mathrm{C}(\beta)$ bonds in $\beta$-peptides (Fig. 2.2A) [43, 55]. With a $\theta$ value fixed at approx. $\pm 60^{\circ}$, trans-2-aminocyclohexyl carboxylic acid 
A<smiles>[R]C(NC(C)C)C(=O)NCC</smiles><smiles>[Te]</smiles>
$\theta \sim+60^{\circ}$

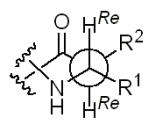

(M) $-3_{14}$ helix<smiles>CC(C)CNC(=O)C1CCCCC1C(C)C</smiles>

(S,S)-ACHC<smiles>[Te]</smiles>

$\theta \sim+60^{\circ}$

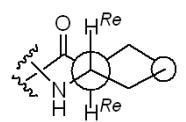<smiles>CCCCCC(=O)C1CCCC1NC</smiles>

$(\mathrm{S}, \mathrm{S})-\mathrm{ACPC}$<smiles>C1CCCCC1</smiles>

$\theta \sim+90^{\circ}$

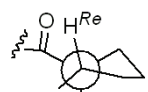

s $-\mathrm{NH}_{\mathrm{H}^{R e}}$

(P)-2.5 12 helix
B

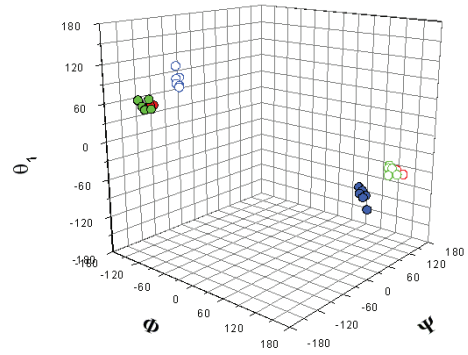

C (M) $-3_{14}$ helix
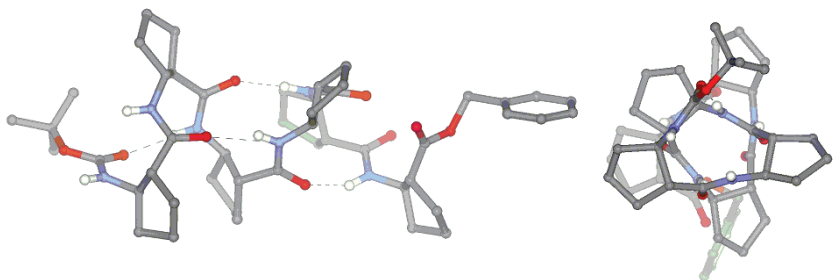

Fig. 2.2 Optimal $\beta$-peptide backbone preorganization for helix formation. (A) Acyclic $\beta^{2,3}$ amino acid residues and $(S, S)-A C H C$ residues which promote gauche conformation arouch the $\mathrm{C}(\alpha)-\mathrm{C}(\beta)$ bond are 14-helix stabilizers. The related five-membered ring ACPC promotes larger $\theta$ values which are not compatible with the 14-helical conformation. (B) Comparison of $\beta$-peptide 14- and 12-helices $(\phi, \theta, \psi)$ conformational space.
(M)-14-helix (values for 1, red closed circles, values for 2, green closed circles), (M)-12helix (values for $\mathbf{3}$, blue closed circles). The enantiomeric positions in the $(\phi, \theta, \psi)$ space are shown as open circles. (C) Side view and top view of the $(M)$-12-helix formed by $(R, R)$ ACPC hexamer 3 as determined by $\mathrm{X}$-ray diffraction (adapted from [59]). Average $(\phi, \theta, \psi)$ values for central residues are $\left(88^{\circ},-85^{\circ}, 98^{\circ}\right)$.

(trans-ACHC), a cyclic $\beta^{2,3}$-amino acid, in which the $\mathrm{C}(\alpha)-\mathrm{C}(\beta)$ bond is part of a 6membered ring, is ideally pre-organized for $3_{14}$ helix formation (Fig. 2.2A) [1, 56, 57]. In contrast, homo-oligomers (e.g. 3) consisting of the smaller ring size trans2-aminocyclopentyl carboxylic acid (trans-ACPC) for which larger values of $\theta$ only are accessible, adopt a stable $12-\left(2.5_{12}\right)$-helix with a $(1 \leftarrow 4) \mathrm{H}$-bonding pattern that differs markedly from the 14-helix (Fig. 2.2) [58-60]. The 14- and 12-helices populated by $(S, S)$-ACHC and related $(S, S)$-ACPC oligomers, respectively have opposite polarity and helical screw sense. The (P)-12-helix display a CD pattern distinct from that of the corresponding 14-helix with a maximum at $204 \mathrm{~nm}$, zero crossing at $214 \mathrm{~nm}$ and minimum at $221 \mathrm{~nm}$.

$\beta$-Amino acids constrained with smaller rings such as cis-aminooxetane carboxylic acids have been shown to promote the formation of a 10-helical structure (e.g. 4) with H-bonds between neighboring amide units $((1 \rightarrow 2) \mathrm{H}$-bonding scheme) [61]. The 10-helix was later identified in short ACHC oligomers (tetramer), suggesting that it could represent a conformational intermediate in the folding pro- 
cess toward the thermodynamically stable 14-helix [62]. The incorporation of cyclic $\omega$-amino acid units to fix the peptide backbone in a geometry favorable to helix formation has since been widely utilized (see also following sections) [63-64]. This approach was recently extended to higher oligoamides such as $\delta$-peptides [66-69]. Conformational search using the methods of ab initio MO theory identified several H-bonded helical backbones accessible to $\delta$-peptides [70]. Experimental validation came from studies with oligomers composed of carbohydrate-derived tetrahydrofuran amino acids with restricted rotation around $\mathrm{C}(\alpha)-\mathrm{C}(\beta)$ and $\mathrm{C}(\beta)-\mathrm{C}(\gamma)$ bonds. In chloroform solution, octamer 5 was found to adopt a well-defined 16-helical fold with $1 \leftarrow 4 \mathrm{H}$-bonding pattern, reminiscent of the $\alpha$-peptide $\pi$-helix [69].
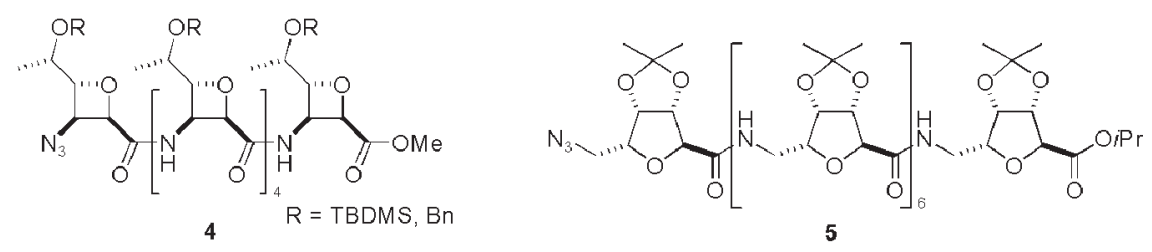

Scheme 2.1

The intrinsic conformational preferences of substituted $\gamma$-amino acid constituents of $\gamma$-peptides derive in part from avoidance of destabilizing syn-pentane interaction [71, 72]. It is recognized that this effect plays a key role in fixing the bioactive conformation of a number of $\gamma$-amino-acid-containing natural products such as Bleomycin $\mathrm{A}_{2}$ [73]. In $\gamma^{4}$-peptides five out of nine conformations generated by rotation around $C(\alpha)-C(\beta)$ and $C(\beta)-C(\gamma)$ bonds are free of syn-pentane interaction.

Adding substitutents at the 2-position (like configuration, see Fig. 2.3A) or at both 2 and 3-positions (like, like relative configuration) reduces to two the number of conformations devoid of syn-pentane interaction (conformation II in Fig. 2.3A is almost identical to that found in the $\gamma^{4}$-peptide 14-helical backbone) and thus reinforces optimal pre-organization for 14-helix formation $\left(\gamma^{2,4}\right.$ and $\gamma^{2,3,4}$. peptides) [45-48]. Other strategies to restrict the conformational space of the $\gamma$ amino acid backbone, such as $\alpha, \beta$-unsaturation (cis-vinologous $\gamma$-peptides [74]), tetrasubtitution [oligomers of 1-(aminomethyl)cyclohexaneacetic acid (gabapentin, Gpn) [75]] cyclic $\gamma$-amino acids (cis- $\gamma$-amino-L-proline oligomers [76]) have been reported.

The $\gamma$-peptide 14 -helical backbone is characterized by large $\psi$ values ranging from 120 to $150^{\circ}$ (or -120 to $-150^{\circ}$ ). This observation led to the finding that substituting urea for the $\mathrm{CH}_{2}-\mathrm{CO}-\mathrm{NH}$ unit in $\gamma$-peptide (substitution of nitrogen for $\mathrm{C}(\alpha)$ in $\gamma$-amino acids) can be used to rigidify the 14-helical fold by fixing the " $\psi$ " angle to a value close to $170-180^{\circ}$ (Fig. 2.3B) [77-80]. In methanol or pyridine solution, the resulting enantiopure $N, N^{\prime}$-linked oligoureas (e.g. 6) adopt a well- 
A

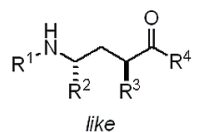

B

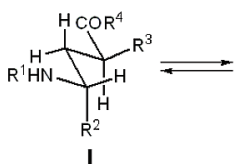

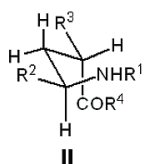

C

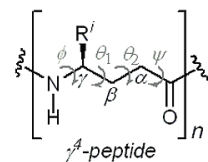

$\gamma^{4}$-peptide (2.6 14 helical)

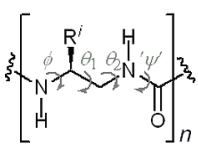

N, N'-oligourea $(2.5,12,14$ helical $)$

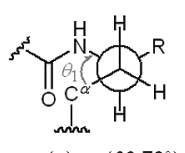

$(+)-s c\left(60-70^{\circ}\right)$

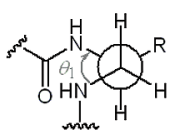

$(+)-\operatorname{sc}\left(60^{\circ}\right)$

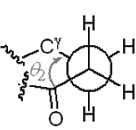

$(+)-\operatorname{sc}\left(60^{\circ}\right)$

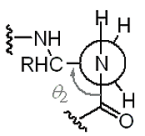

$\sim 90^{\circ}$

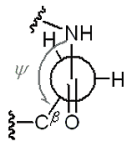

$\sim-140^{\circ}$

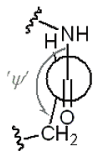

ap $\left(-170^{\circ}\right)$
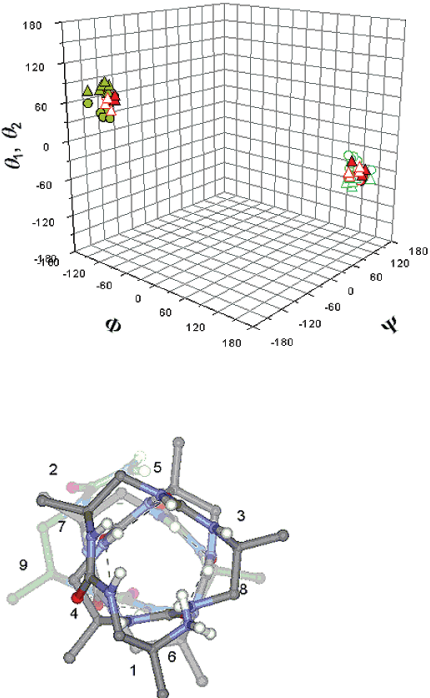

D

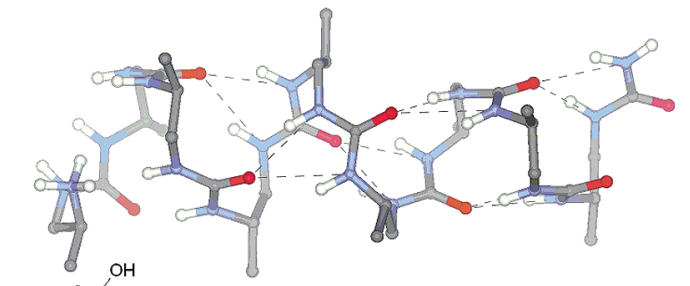

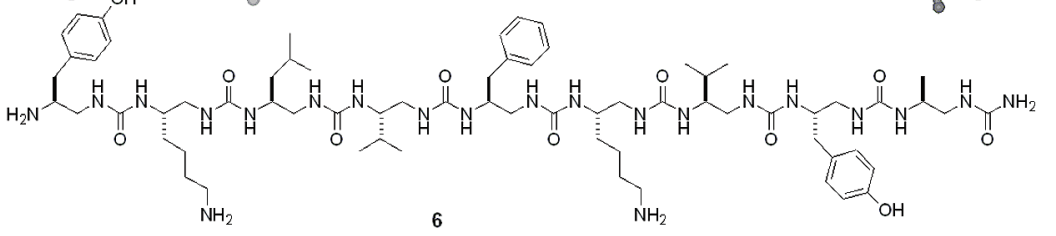

Fig. 2.3 (A) The two conformations free of destabilizing syn-pentane interaction [71, 72] in 2,4-disubstituted $\gamma$-amino acid derivatives with like configuration. Conformation II is close to that found in the $\gamma^{4}$-peptide 14helical backbone (see Fig. 2.1) (B) Structural analogy between the $\gamma^{4}$-peptide and $N, N^{\prime}$ linked oligourea backbones. (C) $\left(\phi, \theta_{1}, \psi\right)$ and $\left(\phi, \theta_{2}, \psi\right)$ maps indicating $\gamma$-peptide 14-helix and $N, N^{\prime}$-linked oligourea 12,14 -helix regions. 14-Helix [values for a $\gamma^{4}$ - and a $\gamma^{2,3,4}$-peptide [45, 47], red closed circles $\left(\phi, \theta_{1}, \psi\right)$ and closed triangles $\left.\left(\phi, \theta_{2}, \psi\right)\right]$, 12,14-helix [values for $\mathbf{6}$, green closed circles $\left(\phi, \theta_{1}, \psi\right)$ and closed triangles $\left.\left(\phi, \theta_{2}, \psi\right)\right]$. The enantiomeric positions in the $\left(\phi, \theta_{1} / \theta_{2}, \psi\right)$ space are shown as open circles/triangles. (D) The $(P)-12,14$-helical structure of $N, N^{\prime}$ linked oligoureas. View along the helix axis and top view of a low energy conformer of nonamer $\mathbf{6}$ as determined by NMR spectroscopy and restrained molecular dynamics calculations in pyridine solution. Average $\left(\phi, \theta_{1}, \theta_{2}, \psi\right)$ values for central residues are $\left(-105^{\circ}, 55^{\circ}, 88^{\circ},-168^{\circ}\right)$. With an internal diameter of $\sim 3 \AA$, the helix is particularly compact and is devoid of empty volume in the interior. Side chains have been partially omitted for clarity (adapted from [78]). 
defined 2.5 helical fold, reminiscent of the $\gamma^{4}$-peptide 14-helix (Fig. 2.3C and D). The structure is held by H-bonds closing both 12- and 14-membered rings (12,14helix) and is characterized by a stable (+)-synclinal arrangement around the ethane bond. $\mathrm{CD}$ spectra recorded in $\mathrm{MeOH}$ display a characteristic signature with an intense maximum near $204 \mathrm{~nm}$ [79]. This is in contrast to related helical $\gamma^{4}$-peptides that do not exhibit any characteristic CD signature.

Alternatively, in a manner analogous to $\alpha$-peptides (see Section 2.2), a helical backbone may be stabilized by creating a covalent linkage (e.g. disulfide bond) between two spatially proximal but sequentially remote side chains (e.g. $i / i+3$ side chains in the $3_{14}$ helix) [81].

\subsubsection{Folding in an Aqueous Environment}

The nature of the solvent can influence to a large extent the propensity of unnatural oligomers to adopt a given H-bonded fold. Conformational studies aimed at identifying new foldamers are often performed in apolar or moderately polar organic solvents (e.g. chloroform, MeCN, pyridine, trifluoroethanol (TFE), $\mathrm{MeOH}$ ). However, determination of a folding pattern in an aqueous environment is highly relevant to applications of foldamers in biology.

Considerable efforts have been undertaken to address this issue in the case of 14- and 12-helical $\beta$-peptides. To increase water solubility of helical $\beta$-peptides composed of ACHC (14-helix promoter) or ACPC (12-helix promoter) oligomers while maintaining the level of backbone pre-organization, Gellman and coworkers developed amino-functionalized versions of trans-2-aminocycloalkane carboxylic acids. $\beta$-Peptides composed of alternating ACHC/DCHC [82] and $\mathrm{ACHC} / \mathrm{APiC}[83]$ residues adopt a robust 14-helical conformation in aqueous solution (Fig 2.4A). Similarly, ACPC/APC [84], ACPC/AP [85], ACPC/3aminomethyl-ACPC [86] repeats promote stable 12-helix formation (Fig 2.4A).

Alternatively, the introduction of a limited number of acyclic $\beta^{3}$ - or $\beta^{2}$-Lys residues $(1 / 3)$ in ACHC- and ACPC-peptides does not preclude the formation of stable 14- and 12-helical structures in aqueous solution [87-89]. Although helicity in water is intrinsically weaker in the absence of strong backbone pre-organization (e.g. $\beta^{3}$-peptides), principles guiding the design of $\beta^{3}$-peptides with high levels of 14-helicity in aqueous solution (e.g. 7, Fig. 2.4B) have recently been delineated by several groups [90-96]. They parallel those formulated for $\alpha$-helical $\alpha$-peptides (see Section 2.2) and include: (i) salt bridge or lactam formation between complementary charged $i / i+3$ side chains (e.g. $\beta^{3}$-HOrn $/ \beta^{3}$-HGlu; $\beta^{3}$-HOrn $/ \beta^{3}$-HAsp; $\beta^{3}$-HDab $/ \beta^{3}$-HAsp; Dab $=2$,4-diaminobutyric acid; Orn $=$ ornithine); (ii) maximization of electrostatic interactions with the helix macrodipole (e.g. by free charged termini, appropriate location of charged side chains, appropriate orientation of salt bridges) and (iii) introduction of $\beta^{3}$-amino acids with high intrinsic 14-helix propensitiy. For noncharged $\beta^{3}$-amino acids, 14-helix propensities have been found to differ significantly from $\alpha$-helix propensities of corresponding $\alpha$ amino acids. Ala is the most $\alpha$-helix-stabilizing $\alpha$-amino acid but the methyl side chain is one of the least 14-helical stabilizing. In contrast, branched side chains of Ile, Thr, and Val which display only moderate to low $\alpha$-helix propensity are all 
A

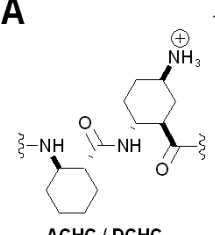

ACHC / DCHC 14-helix

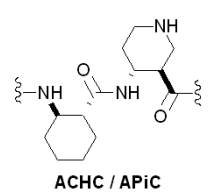

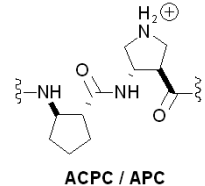

ACPC / APC 12-helix
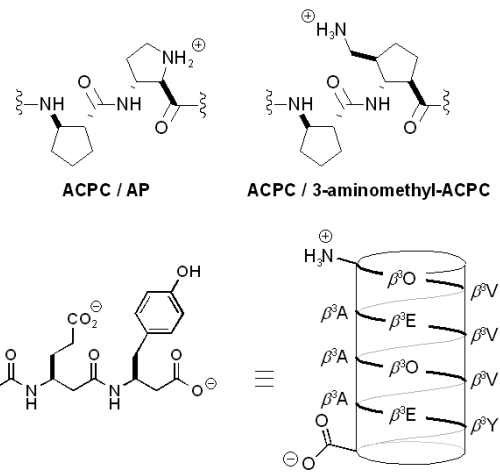

B

B

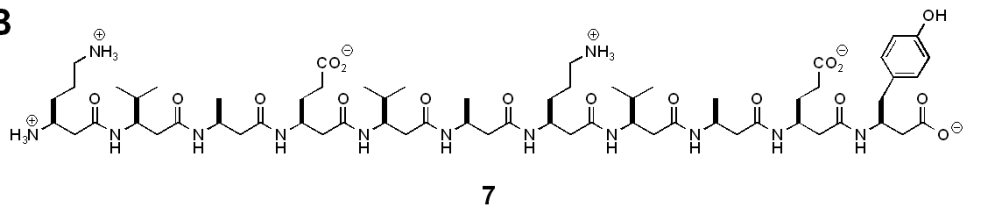

chains, favorable electrostatic interactions with the helix macrodipole and side-chain formation in water. (A) Using aminofunctionalized versions of trans-2aminocycloalcane carboxylic acids [82-86]. (B) De novo design of $\beta^{3}$-peptide with high level of 14-helicity in aqueous solution by combining: salt bridges between $i / i+3$ side branching ( $\beta^{3}-\mathrm{HVal}$ residues). Mean residue ellipticity of 7 measured by CD at $214 \mathrm{~nm}$ : $\Theta_{214}=-13320 \mathrm{deg} \mathrm{cm}^{-2} \mathrm{dmol}^{-1}$ in $1 \mathrm{mM}$ sodium phosphate/borate/citrate, $\mathrm{pH} 7.0$ at $25^{\circ} \mathrm{C}$ [95].

strongly 14-helix stabilizing. Intramolecular interhelical hydrophobic interactions (in a $\beta^{3}$-peptide two-helix bundle) have also been shown to increase 14-helicity in aqueous solution [97].

If $\beta$-peptides are indisputably the best characterized helical aliphatic peptide foldamer system in aqueous solution so far, some of the aromatic foldamers described in Chapter 1 fold into water even better than they do in organic solvents without any specific adjustment of their structure. It remains to be seen whether other foldamers based on remote intrastrand $\mathrm{H}$-bonds can be designed to adopt robust helical structures in water.

\subsubsection{Dynamics of $\beta$ - and $\gamma$-Peptide Helices: Evidence for Noncooperative Folding/Unfolding Processes}

The unfolding and folding mechanisms of 14-helical $\beta$-, $\gamma$-peptides and analogs have been investigated in polar solvents by various approaches. Temperaturedependent-CD and NMR measurements suggest that 14-helical $\beta$-peptides [44] and also 14-helical $\gamma^{2,3,4}$-peptides [48] and helical $N, N^{\prime}$-linked oligoureas [7779], undergo noncooperative unfolding upon heating in $\mathrm{MeOH}$. For instance, the intensity of the extremum at $215 \mathrm{~nm}$ for $\beta$-peptide $\mathbf{1}$ decreases linearly (by ca $12 \%$ per $20 \mathrm{~K}$ ) and noncooperative break-up of the structure is observed between 295 and $333 \mathrm{~K}$. The scan, which is reversible, suggests that the unfolding and folding route of the helix must be reversible [44]. Insight into the dynamics of $\beta$-peptides and evidence for reversible folding were also provided by molecular dynamics (MD) simulations (GROMOS96 force-field [98], reviewed in Chapter 6) in explicit solvents and at different temperatures [99-104]. By simulating on a 
time scale that is long compared with the lifetime of any specific conformation (typically $\geq 50 \mathrm{~ns}$ ), it has been possible to determine the population and average lifetimes of the different conformations observed and to explore paths and rates of interconversion between the experimentally observed 14-helix conformation and (partially) unfolded conformations $[102,104]$. In the course of a 50-ns simulation and irrespective of its initial conformation, $\beta$-peptide 1 folds rapidly (in the order of a few nanoseconds) into the experimentally observed 14-helix conformation (maximum lifetime $\sim 10 \mathrm{~ns}$ at $340 \mathrm{~K}$ ) which is populated $50 \%$ of the time at $340 \mathrm{~K}[99,101]$.

Recent progress towards the synthesis of the spin-labeled $\beta^{2,3}$-amino acid trans- $\beta$-TOAC (4-amino-1-oxyl-2,2,6,6-tetramethylpiperidine-3-carboxylic acid) and its incorporation into ACHC-peptides at $i / i+3$ positions suggest that it might soon be possible to use electron spin resonance (ESR) to investigate further the structures and folding transitions in 14-helical $\beta$-peptides [105].

\subsection{2}

\section{Extended Helices with Small H-bonded Rings Centered at a Single Residue}

This section focuses on small (generally $\leq 10$ atoms) pseudocycles with $1 \leftarrow 3 \mathrm{H}$ bond interaction as potent helix building blocks. The pseudocycle is centered at the $(i+1)$ residue, with an $\mathrm{H}$-bond joining the $\mathrm{C}=\mathrm{O}$ and $\mathrm{NH}$ groups at positions $i$ and $i+2$ respectively (Fig. 2.5A). This H-bonding scheme recurs in the $\beta$ - and $\gamma$ peptide lineage subject to the presence of strong pre-organization structural elements in monomeric units (e.g. ring, backbone or side chain heteroatoms).

\subsubsection{1 $\alpha$-Peptides: the $\gamma$-Helix}

In $\alpha$-peptides, $1 \leftarrow 3 \mathrm{H}$-bond interaction corresponds to a seven $\left(\mathrm{C}_{7}\right) \mathrm{H}$-bonded ring, i.e. the $\gamma$-turn $\left(\phi \sim+70^{\circ}, \psi \sim-70^{\circ}\right)$ or the more stable inverse $\gamma$-turn $\left(\phi \sim-70^{\circ}, \psi \sim+70^{\circ}\right)$ according to the equatorial or axial orientation of the side chain [106]. They are quite common structuring elements of cyclic peptides, and can also be observed in crystallized proteins, although much less frequently than $\beta$-turns. A series of consecutive inverse $\gamma$-turns generates a theoretical 2.27 -helix called $\gamma$-helix [107] (Fig. 2.5B), which has, however, not been detected in natural peptides or proteins so far. Recently, a first step was accomplished towards the construction of an artificial $\gamma$-helix template. Jiménez et al. showed that the dipeptide Ac-L-Pro-D-C $\mathrm{C}_{3}$ Dip-NHMe (8) adopts two consecutive $\gamma$-turns, induced by the presence of the $\mathrm{D}$-form of the cyclopropane amino acid $\left(\mathrm{c}_{3}\right.$ Dip) derivative (Fig. 2.5B) [108].

\subsubsection{2 $\omega$-Peptides with Specific Conformation-stabilizing Elements}

$\boldsymbol{\beta}$-Peptides: the 8-helix The world of $\beta$-peptides is mostly associated with the prominent 12- and 14-helical folds. Considering that their topology excludes the presence of axial substituents (see Fig. 2.2), $\beta$-peptides consisting of geminally disubstituted amino acids or of $\beta^{2,3}$-amino acids of unlike configuration (see 
A

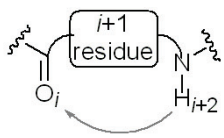

B

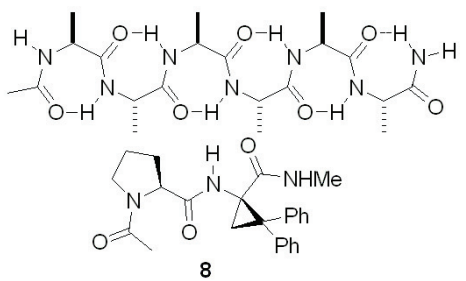

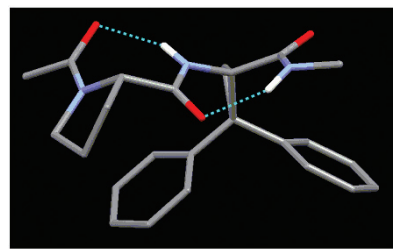

C

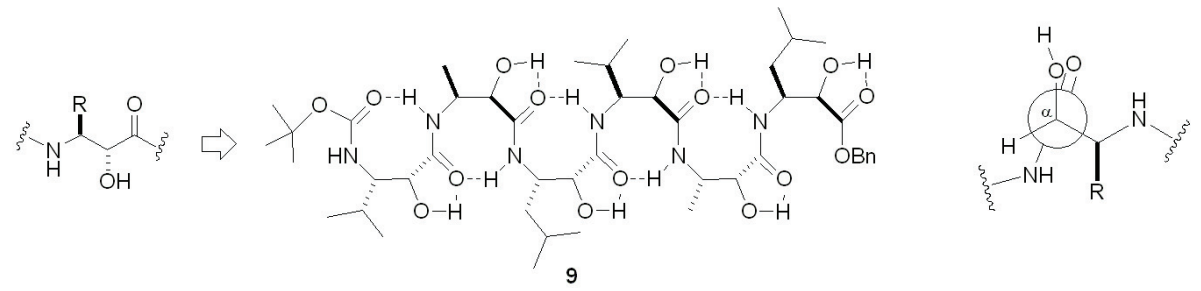

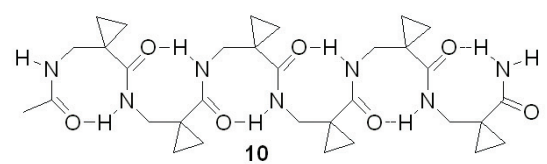

10

E

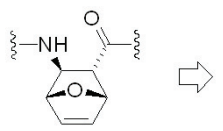

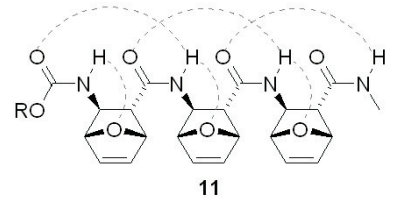

11

Fig. 2.5 (A) $1 \leftarrow 3 \mathrm{H}$-bonding scheme in $\omega$-peptides and analogs. (B) The $\alpha$-peptide $\gamma$-helix and the two consecutive $C_{7}$ turns observed experimentally for dipeptide 8 in the solid state [108]. (C-E) Expansion of the $\alpha$-peptide $C_{7}$ structure by the addition of one backbone atom: the $\mathrm{C}_{8} \mathrm{H}$-bonded conformations of $\beta$-peptides 9-11 consisting of specific conformation-stabilizing elements: (C) $(2 R, 3 S)-\alpha$-hydroxylated $\beta^{2,3}$-amino acid [109], (D) 1-aminomethylcyclopropanecarboxylic acid [50], and (E) trans-oxabornene$\beta$-amino acid residues (B3LYP/6-311++G** minimum energy conformation) [110].

also Section 2.5) cannot fit in any of the two folds. Seebach and collaborators found that $\beta$-peptides consisting of $(2 R, 3 S)$ - $\alpha$-hydroxylated $\beta^{2,3}$-amino acid residues (e.g. 9) exist in polar solvent as a helical conformation based on repetitive 8-membered $\mathrm{H}$-bonded rings resulting from $1 \leftarrow 3 \mathrm{H}$-bond interactions $\left(\mathrm{C}=\mathrm{O}_{i} \cdots \mathrm{H}-\mathrm{N}_{i+2}\right)$ [109]. The structure is probably further stabilized by an additional interaction between $\mathrm{C}=\mathrm{O}_{i} \cdots \mathrm{H}-\mathrm{O}_{i}$ (Fig. 2.5C). A remarkably similar $\mathrm{C}_{8}$ based conformation was reported for $\beta^{2,2}$-substituted oligomers consisting of 1-aminomethylcyclopropanecarboxylic acid residues (Fig. 2.5D) [50]. X-ray diffraction studies of short chain oligomers revealed that orbital hyperconjugation between the $\sigma$-bonding orbitals (HOMO) of the cyclopropane ring and the $\pi^{*}$ nonbonding orbital (LUMO) of the carbonyl constrained $\psi$ values close to $0^{\circ}$ (bisected 
conformation), thus favoring a $\mathrm{C}_{8} \mathrm{H}$-bonding pattern. A ribbon-like secondary structure was extrapolated from these data.

Independently, using ${ }^{1} \mathrm{H}$ NMR and density functional theory computations, Klein and co-workers concluded that the $\beta$-peptide consisiting of transoxabornene- $\beta$-aminoacid (e.g. 11, Fig. 2.5E) also adopts a $\mathrm{C}_{8}$-based helix conformation [110]. These results show that cyclohexyl ring bridging and unsaturation impose angular constraints that translate the robust $33_{14}$-helix sustained by transACHC- $\beta^{2,3}$ amino acid units (see Section 2.3.1.2) [1, 56, 57], into a new folding pattern. Additional $\mathrm{H}$-bond contacts between amide $\mathrm{NHs}$ and the ring oxygens were also hypothesized. Altogether, these results do not question the proposal formulated by Gellman [41] that $1 \leftarrow 3 \mathrm{H}$-bonding between nearest-neighbor amide groups in $\beta$-peptides is not favored, but rather suggest that extra-interaction or specific angular constraints can overcome this general feature.

$\gamma$-Peptides According to model studies [41], $\gamma$-peptides have higher propensities than $\beta$-peptides to populate conformations stabilized by H-bonding between nearest neighbor amide groups. Several examples of secondary structures stabilized by $1 \leftarrow 3 \mathrm{H}$ bonds have been identified in designed $\gamma$-peptides incorporating various levels of backbone pre-organization [74-76, 111]. In the case of gabapentin (Gpn), a $\gamma^{3,3}$-geminally disubstituted amino acid, both $\mathrm{C}(\alpha)-\mathrm{C}(\beta)$ and $\mathrm{C}(\beta)-\mathrm{C}(\gamma)$ bonds are locked in a gauche conformation with $\theta_{1} \sim \theta_{2} \sim \pm 60^{\circ}$ [75]. In the solid state, $\mathrm{Gpn}$ oligomers populate $\mathrm{C}_{9} \mathrm{H}$-bonded conformations. Because the molecules are achiral, two sets of dihedral angles $(+)$ and $(-)$ of opposite values can be associated with the $\mathrm{C}_{9}$-pseudocycle. The structure of the dimer shows a $(+,+)$ arrangement, which can be extrapolated to a 2.7-helix, whereas the structure of the tetramer corresponds to a heterochiral sequence $(+,-,+,-)$ leading to a ribbon structure (Fig. 2.6A). In all cases, the secondary structures rely on consecutive $\mathrm{C}_{9} \mathrm{H}$-bonded rings [75].

A related $\mathrm{C}_{9}$-ribbon type structure has been postulated on the basis of NMR spectroscopy data in $\mathrm{H}_{2} \mathrm{O}$ for $\gamma$-peptide oligomers of cis- $\gamma$-amino-L-proline (Fig. 2.6B) [76]. In the proposed secondary structure of 12 , the two amide bonds connected to $\alpha$ - and $\gamma$-positions of each proline residue are in the same plane, perpendicular to the average plane of the proline rings. The solid phase synthesis approach which authorizes facile incorporation of a variety of acyl and alkyl side chains at the $\gamma$-amino position is highly modular.

The carbofuranosyl group was used by Sharma and Kunvar as a conformationstabilizing side chain to enforce the backbone of $\beta$ - and $\gamma$-peptides into welldefined folded conformations (see also peptides 16 and 22 in Sections 2.4.2.2 and 2.4.3). A left-handed 9-helix with $1 \leftarrow 3 \mathrm{H}$-bonding pattern (Fig. 2.6C) was identified from NMR studies in $\mathrm{CDCl}_{3}$ solution and molecular dynamics calculations for a hybrid $\gamma$-hexapeptide (13) with alternating carbofuranosyl- $\gamma^{4}$-aminoacid and $\gamma$-aminobutyric acid (GABA or $\gamma$-Gly). It is worth mentioning that the corresponding $\beta$-peptides made of alternating $(3 S)$-carbofuranosyl- $\beta^{3}$-amino acid and $\beta$-HGly residues adopt a mixed helical structure with $(M)$-helicity. (see Section 2.4.2.2). 
A<smiles>CNCC1(CC(C)=O)CCCCC1</smiles>

gabapentin

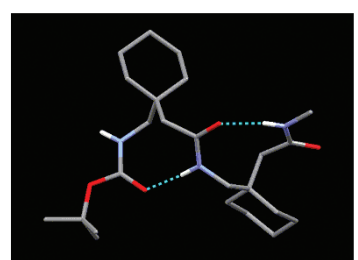

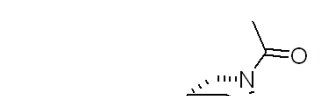

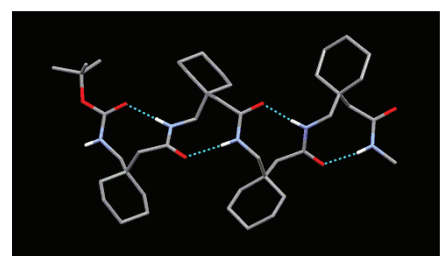

B<smiles>[Y]C1CC(C(=O)O)N([R])C1</smiles>

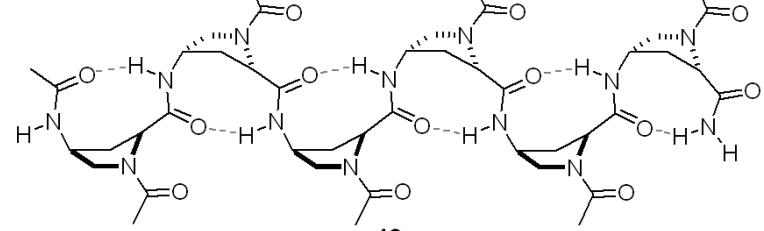

12

C

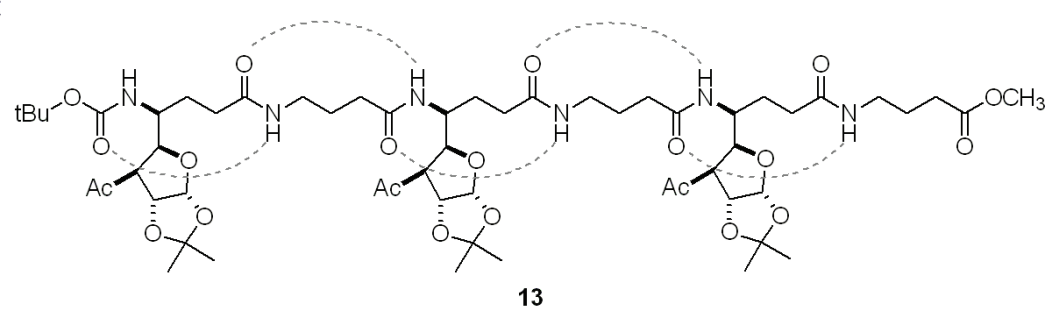

Fig. 2.6 $\mathrm{C}_{9} \mathrm{H}$-bonded conformations of $\gamma$-peptides. (A) Gabapentin oligomers. Structure of dimer and tetramer in the solid state [75]. (B) Oligomers of cis- $\gamma$-amino-L-proline [76]. (C) $\gamma$-Hexapeptide 13 with alternating carbofuranosyl- $\gamma^{4}$-aminoacid and $\gamma$-Gly residues [111].

\subsubsection{Stabilizing Local Backbone Conformation by Inverse-Bifurcation Involving an Additional Heteroatom}

Oligo $\alpha$ - and $\beta$ - and $\boldsymbol{\gamma}$-aminoxyacids As already mentioned in Section 2.3.1.2 for $N, N^{\prime}$-oligoureas ( $\gamma$-peptide lineage), replacing carbon atoms in an $\omega$-peptide backbone with heteroatoms represents a promising opportunity to design new foldamers. $\alpha$-Aminoxypeptides formerly obtained by substitution of oxygen for the $\beta$-carbon atoms within the $\beta$-peptide backbone (Fig. 2.7A) have been investigated in depth by ab initio quantum-mechanical calculations and molecular dynamics simulation. This theoretical work predicted that a $\mathrm{C}_{8} \mathrm{H}$-bonded ring $(\mathrm{N}-\mathrm{O}$ turn, Fig. 2.7A) should stabilize a 1.8 -helix conformation in homochiral segments [112, 113] (Fig. 2.7B), at least in aprotic solvents [114]. Spectroscopic studies on a series of oligomers supported these predictions and established that such an helical conformation occurs in oligomers as short as a trimer [115]. The high stability of the helix was interpreted as the result of the replacement of the amide bonds by "amidoxy" bonds in which the strong withdrawing effect of the oxygen atom considerably enhances the acidity of the NHs and the strength of the $\mathrm{H}$ 
A<smiles>CCNC(=O)CCNC(=O)NC</smiles>

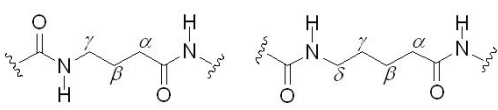

$\beta$ peptide

-peptide

$\delta$-peptide

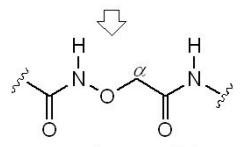

5

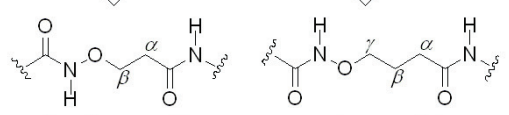

$\beta$-aminoxypeptide

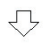

$\gamma$-aminoxypeptide

$\prod_{\beta^{2} \text {-peptide }}^{\mathrm{N}} \sum_{0}^{\mathrm{R}}$

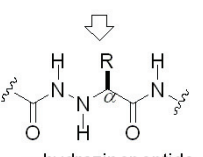

$\alpha$-hydrazinopeptide

$$
\text { aza- } \beta^{\beta} \text {-peptide }
$$

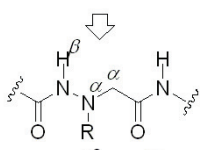

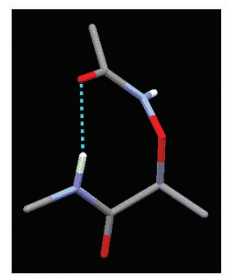
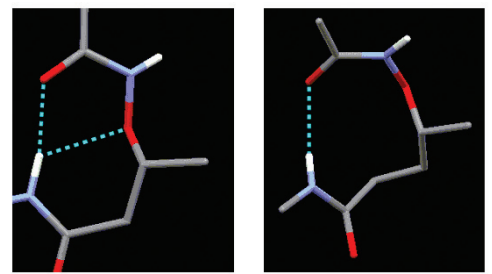

\section{B}

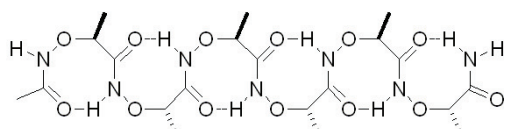

C
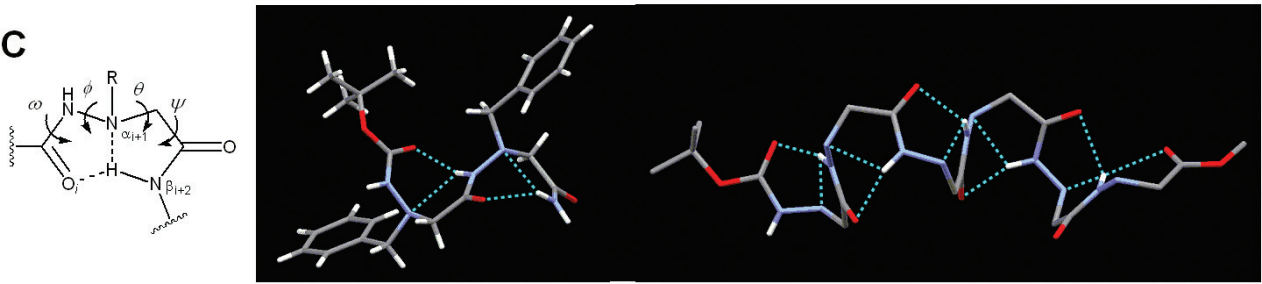

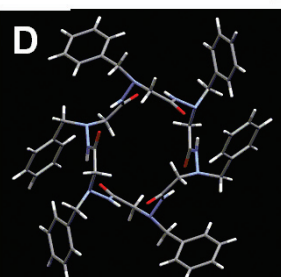

Top view

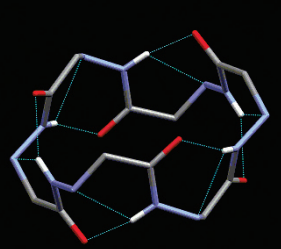

bird's-eye view

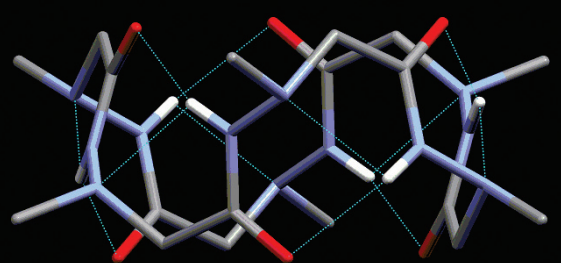

side view
Fig. 2.7 Foldamers with propensities for $1 \leftarrow 3 \mathrm{H}$-bonded conformations by introduction of heteroatoms in the backbone of $\omega$-peptides. (A) General formulae and comparison with related $\omega$-peptide backbones. X-ray structures of $\mathrm{N}-\mathrm{O}$ turns in $\alpha-, \beta$-, $\gamma$-aminoxy peptides $[112,113,117$, 120]. (B) The $\mathrm{C}_{8} \mathrm{H}$-bonded conformation (1.88-helix) of $\alpha$-aminoxy peptides [113].
(C) The hydrazino turn and solid state conformation of aza- $\beta^{3}$-peptides (dimer and hexamer) [125]. (D) Solid state conformation of an aza- $\beta^{3}$-cyclohexapeptide showing the uninterrupted framework of bifidic $\mathrm{C}_{8}$ pseudocycles. For clarity, side chains are omitted on bird's-eye view and side view [128]. 
bonds. In addition, the lone pair electron repulsion in the $\mathrm{N}-\mathrm{O}$ segment reduces the flexibility of the backbone, which stabilizes the secondary structure, and promotes H-bonding between adjacent residues by selecting favorable dihedral angles. The crystal structure of a model trimer, in good agreement with the calculated geometry of the $\mathrm{N}-\mathrm{O}$ turn, comfirm this analysis [116].

Small models of $\beta$-aminoxypeptides [117-119] and $\gamma$-aminoxypeptides [120] (Fig. 2.7A) were subsequently investigated by the group of Yang. FT-IR and NMR spectroscopy as well as X-ray diffraction studies also indicated a net preference for $1 \leftarrow 3 \mathrm{H}$-bond interaction, leading respectively to the formation of $\mathrm{C}_{9}$ and $\mathrm{C}_{10}$ pseudocycles (Fig. 2.7A). The $\mathrm{C}_{9}$ ring is clearly an inverse bifurcated system where the $\mathrm{NH}_{i+2}$ is $\mathrm{H}$-bonded to both $\mathrm{O}_{i+1}$ and $\mathrm{C}=\mathrm{O}_{i}\left(\mathrm{~d}\left(\mathrm{~N}_{i+2}-\mathrm{O}_{i+1}\right)=2.5 \AA\right)$. It is not the case for the $\mathrm{C}_{10}$ pseudocycle (right) where the distance between $\mathrm{O}_{i+1}$ to $\mathrm{NH}_{i+2}$ is too long $\left(\mathrm{d}\left(\mathrm{N}_{i+2}-\mathrm{O}_{i+1}\right)=3.3 \AA\right)$.

Hydrazinopeptides Oligomers of hydrazinoacetic acid derivatives are $\mathrm{aza}^{3}$ analogs of $\beta^{2}$-peptides (Fig. 2.7A). Secondary structure ensembles for these compounds have been examined at various level of $a b$ initio MO theory by Günther and Hofmann [121]. The variety of H-bond networks in hydrazinopeptides is increased compared with $\beta$-peptides because of the additional $\mathrm{N}^{\alpha} \mathrm{H}$ centers which act as potential $\mathrm{H}$-bond donors and $\mathrm{H}$-bond acceptors. A $\mathrm{C}_{8}$ based helical conformation (calculated $1.75_{8}$-helix), similar to that observed for $\alpha$-aminoxy peptides, emerged in one mode of calculation. In all other cases the most favorable calculated secondary structure is a new 14-helix that topologically differs from the $\beta$ peptide 14-helix because of the participation of the lone pair of the $\mathrm{sp}^{3} \mathrm{~N}^{\alpha}$ atom in the stabilization of the 14-membered H-bonded ring. Although the synthesis of chiral hydrazinopeptides remains challenging, a series of hydrazinopeptides up to the hexamer have been prepared by Seebach and co-workers [122]. In $\mathrm{MeOH}$, the hexamer displays a CD signature that resembles that of the corresponding 14-helical $\beta^{2}$-peptide. However, poor signal dispersion and fast exchange between NHs precluded detailed NMR studies and subsequent molecular modeling. These observations suggest dynamic interconversion between competitive conformations.

Aza- $\beta^{3}$-peptides Aza- $\beta^{3}$-peptides [123], the $\mathrm{aza}^{3}$-analogs of $\beta^{3}$-peptides, are oligomers of $N^{\alpha}$-substituted hydrazinoacetic acid (Fig. 2.7A, right). The main feature of this unnatural backbone is that nitrogen atoms bearing the side chains are $\mathrm{sp}^{3}$ hybridized. As a result, aza- $\beta^{3}$-peptides are chiral molecules of undefined configuration. In $\mathrm{CDCl}_{3}$ solution as well as in the solid state, their backbone is structured by a continuous set of $\mathrm{C}_{8}$ pseudocycles (hydrazinoturn [124] or N-N turn) [125]. Examination of X-ray structures of a dimer and a hexamer (Fig. 2.7C) reveals that the former corresponds to a homochiral sequence (both nitrogen centers have the same absolute configuration) that defines an incipient extended $1.75_{8}$-helix whereas the latter is characterized by an heterochiral arrangement $(R, R, S, S, R, R$ chiral sequence) that drives a more folded conformation. In solution, aza- $\beta^{3}$-peptides equilibrate between all possible chiral sequences, all of 
which share the same $\mathrm{C}_{8}$ based $\mathrm{H}$-bond network. The structural resemblance between $\alpha$-aminoxypeptide and aza- $\beta^{3}$-peptide backbones which both rely on the formation of a $\mathrm{C}_{8} \mathrm{H}$-bonded network is striking. In both cases, the presence of the two adjacent heteroatoms is the driving force of the folding process. In aza- $\beta^{3}$ peptide $\mathrm{C}_{8}$ pseudocycles, the ${ }^{\alpha} \mathrm{N}_{i+1} \cdots \mathrm{H}-{ }^{\beta} \mathrm{N}_{i+2}$ distance $(\sim 2.25 \AA)$ is typical of a $\mathrm{H}$ bond but the corresponding angle $\left(\sim 110^{\circ}\right)$ is distorted relative to the expected value for a standard $\mathrm{H}$ bond. The same holds true for the $\mathrm{N}-\mathrm{O}$ turn $\left(\mathrm{d}\left({ }^{\alpha} \mathrm{O}_{i+1} \cdots \mathrm{H}-{ }^{\beta} \mathrm{N}_{i+2}\right)\right)$. This interaction has been shown to play a crucial role in the stabilization of the secondary structure [126]. The $C_{8}$ pseudocycle of aza- $\beta^{3}$ peptide and probably the $\mathrm{N}-\mathrm{O}$ turn can thus be described as inverse bifurcated systems combining interactions between nearest and non-nearest neighbors [127]. Conformational analyses of aminoxy- and hydrazino-peptides, and also studies of $N, N^{\prime}$-linked oligoureas described in Section 2.3.1.2 illustrate that the amide linkage is not the only polar bond that can sustain a robust intramolecular H-bond network for the design of self-organizing oligomers.

It is noteworthy that the intrinsic features and conformational preferences of linear aza- $\beta^{3}$-peptides can be exploited to generate macrocyclized derivatives with remarkable efficiency (for example of self-templated macrocycles, see Chapter 1). This result can be rationalized by invoking a dynamic process, i.e. the ability of linear precursors to populate heterochiral sequences ideally pre-organized for cyclization. The resulting macrocycles retain the alternated chiral sequence (the pyramidal inversion of the chiral nitrogen atoms is now considerably slowed down) as well as the basic $C_{8}$ structure $\left(C_{3}\right.$-symetric hexamer, Fig. 2.7D) [128]. The solid state intramolecular organization of the macrocycles perfectly reflects the major conformation present in solution $\left(\mathrm{CDCl}_{3}\right)$.

To conclude this section, it is interesting to point out that, in contrast to the natural $\alpha$-peptides, $1 \leftarrow 3 \mathrm{H}$-bond interaction patterns consistently sustain secondary structures in different classes of designed $\omega$-peptides and their related analogs. A survey of the present literature also emphasizes how much folding can be oriented through slight structural modulations, such as stereochemical modifications, side chain tuning, and backbone alteration, which all subtly modulate the set of weak intramolecular interactions and, in the end, the shape of the molecules.

\section{4}

\section{Oligoamide Mixed Helices}

In contrast to common periodic peptide helices in which components along the helix axis of backbone $\mathrm{C}=\mathrm{O}$ bond vectors point in the same direction, a unique feature of mixed helices is the alternating direction of the $\mathrm{C}=\mathrm{O}$ bonds along the sequence that results in the formation of a $\beta$-sheet-type H-bonding pattern. Mixed helices are thus characterized by a small macrodipole which implies that they are energetically disfavored in a polar environment compared with common periodic helices that have their $\mathrm{H}$ bonds oriented in the same direction. 


\subsection{1}

\section{The $\alpha$-Oligopeptide Precedent: from Antibiotic Gramicidin A to Poly-Gln Aggregates} in Huntington's Disease

Mixed helices, also termed $\beta$-helices by virtue of this similarity to $\beta$-sheet type structures, were proposed in the early 1970s independently by Ramachandran and Chandrasekharan [129], and Urry [130] for $\alpha$-oligopeptides with a regularly alternating sequence of $\mathrm{D}$ and $\mathrm{L}$ residues (D,L-peptides) such as the linear pentadecapeptide antibiotic gramicidin A (HCO-Val-Gly-Ala-D-Leu-Ala-D-Val-Val-D-ValTrp-D-Leu-Trp-D-Leu-Trp-D-Leu-Trp-NH- $\left.\left(\mathrm{CH}_{2}\right)-\mathrm{OH}\right)$, i.e. by repeating a pair of $(\phi, \psi)$ angles with values lying in the allowed $\beta$-sheet region of the Ramachandran map for $\mathrm{L}$ and $\mathrm{D}$ residues, respectively. The $\mathrm{H}$ bonds are formed alternatively in forward and backward directions along the sequences thus closing intertwined pseudo rings of different sizes (Fig. 2.8). $\beta$-Helices formed by D,L-peptides are characterized by their structural polymorphism [131-135]. They can be either right- or left-handed depending on parameters such as sequence, length and environment. Various periodicity and hence pore size have been predicted and found experimentally. Finally, $\beta$-helices can exist either as single helices stabilized by parallel $\mathrm{H}$ bonds or as parallel (or antiparallel) double helices. Gramicidin A, for example, depending on its surrounding environment has been found to form either single stranded or double stranded $\beta$-helical conformations with residues per turn ranging from 5.6 to 7.2 [136-139].

Proteins also fold into right- and left-handed $\beta$-type helical structures with larger periodicities [140-142]. The first parallel $\beta$-helix fold (right-handed) was discovered by Yoder and co-workers in the structure of Pectate Lyase C [140]. The repeating unit (i.e. $\beta$-helical turn) in such $\beta$-helices is formed by three strand segments connected by three loops and generally comprises $15-23$ residues. A large "loopless" $\beta$-helical nanotube with 20 residues per helical turn has been proposed by Perutz and co-workers to account for the X-ray diffraction patterns of fibers of a poly-L-Gln peptide (exon-1 peptide of huntingtin) [143]. In addition to being relevant to Huntington's disease, this model may also serve to interpret structures of amyloid fibrils associated with various neurodegenerative diseases. It is worth noting that this structure which features repetition of a pair of $(\phi, \psi)$

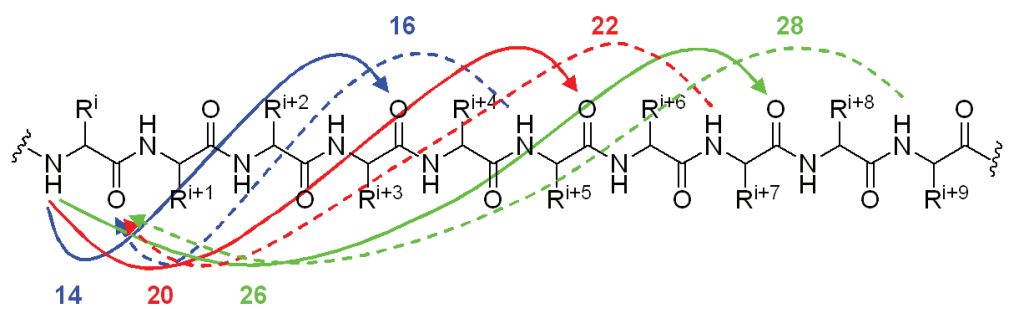

Fig. 2.8 $\mathrm{H}$-bond patterns associated with mixed helical secondary structures in $\alpha$-polypeptides. 
angles with nearly opposite values $\left(\phi_{1}=160^{\circ}, \psi_{1}=-170^{\circ} ; \phi_{2}=-161^{\circ}, \psi_{2}=\right.$ $\left.178^{\circ}\right)$; is remarkably close to a $\mathrm{D}$, L-peptide $\beta$-helical fold.

\section{4 .2}

\section{Introducing Periodicity at the Level of a Dimer Unit in $\beta$-Peptides leads to a Remarkably Stable Mixed Helical Fold}

Early studies by Seebach and co-workers established that, by analogy to $\beta$-helical $\alpha$-peptides, $\beta$-peptides with an alternating substitution pattern adopt a mixed helical conformation [55, 144, 145]. The resulting structure which consists of 10- and 12-membered $\mathrm{H}$-bonded pseudo rings alternating in forwards and backwards direction, respectively has only a small resulting macrodipole. This particularly robust mixed helical fold was subsequently observed for other $\beta$-peptides (Fig. 2.9) exhibiting periodicity at the level of a dimeric unit [146-148].

\subsubsection{By Mixing $\boldsymbol{\beta}^{2}$ - and $\boldsymbol{\beta}^{3}$-Amino Acids}

The finding that the conformational preferences of "mixed" $\beta$-peptides composed of alternating $\beta^{3}$ - and $\beta^{2}$-amino acid residues differed from that of the corresponding homopolymers consisting exclusively of $\beta^{3}$ - or $\beta^{2}$-amino acid residues (i.e. the $3_{14}$ helix) was largely unexpected [144]. In $\mathrm{MeOH}, \beta$-peptides with $(S)$ -

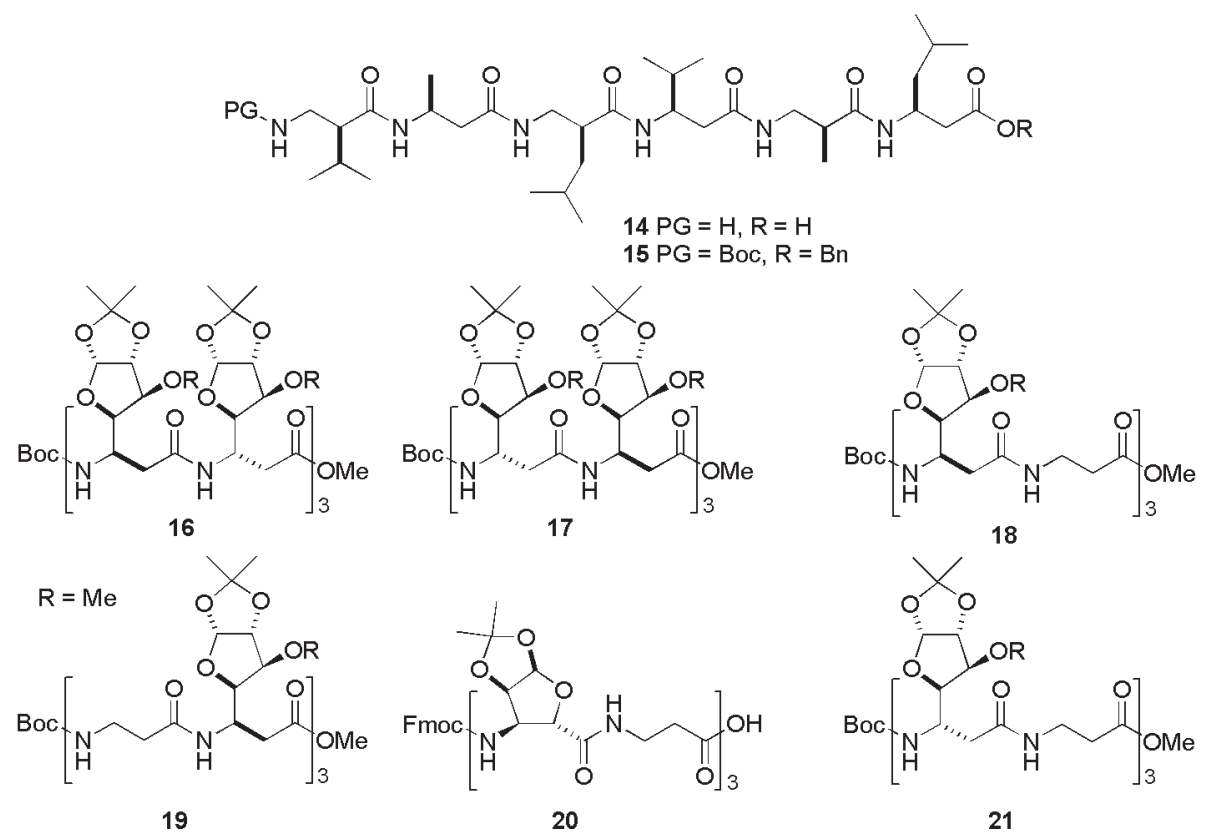

Fig. 2.9 Mixed 12/10- (10/12-) helix forming $\beta$-peptides [144-148]. 
$\beta^{2} / \beta^{3}$ (or $(S)-\beta^{3} / \beta^{2}$ ) dipeptide repeats such as 14 and 15 did not display the CDpattern characteristic of the $3_{14}$ helix. Their CD spectra showed an intense maximum near $205 \mathrm{~nm}$ and no zero-crossing. The dispersion of the chemical shifts as well as the large ${ }^{3} \mathrm{~J}(\mathrm{H}-\mathrm{C}(\alpha), \mathrm{H}-\mathrm{C}(\beta))$ values $(>10 \mathrm{~Hz})$ in their NMR spectra recorded in pyridine and $\mathrm{CD}_{3} \mathrm{OH}$ indicated that at least one stable secondary structure was populated. ROESY experiments revealed a NOE pattern substantially different from that of the $3_{14}$ helix with no $i / i+3$ NOE crosspeaks and new $i / i+2$ connectivities not compatible with the $3_{14}$ helix. Restrained MD calculations based on NOEs and $J$ values yielded a unique mixed helical structure with alternating intertwined 12- and 10-membered H-bonded rings. The helical screw sense was opposite to that of the related $3_{14}$ helix and the overall macrodipole was strongly reduced because of alternating orientations of backbone carbonyl groups. The 12/10-structure of a low energy conformer of $\beta^{2} / \beta^{3}$-peptide 14 [55, 144] and detailed representations of the 12- and 10-membered pseudocycles are shown in Fig. 2.10. Comparison of the 10/12-helix turns with the corresponding 14-membered ring of the 314 -helix reveals a common $(+)$-synclinal arrangement $\left(\theta_{1} \sim 60^{\circ}\right)$ around the central $\mathrm{C}(\alpha)-\mathrm{C}(\beta)$ bond for each amino acid constituents. However, whereas both $\phi$ and $\psi$ angles are negative for $\beta$-amino acids in the regular 3 -helix, $\beta^{2}$-amino acid residues have a positive $\phi$ value and $\beta^{3}$-amino acid residues a positive $\psi$ value in the $12 / 10$-helix.

The tendency is that in the absence of any adjacent substituent on the two sides of an amide bond, the 12-membered turn is favored, the 10-membered being formed when the amide bond is flanked by substituted carbons (Fig. 2.10). In fully protected 15 , the $\mathrm{NH}$ of residue 1 is engaged in the formation of an addi-

A

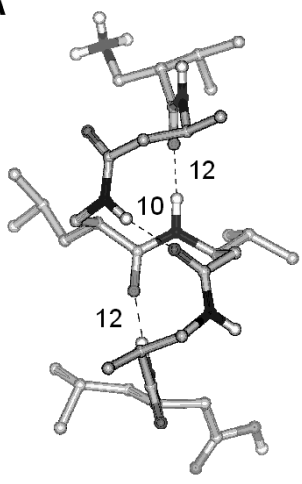

B

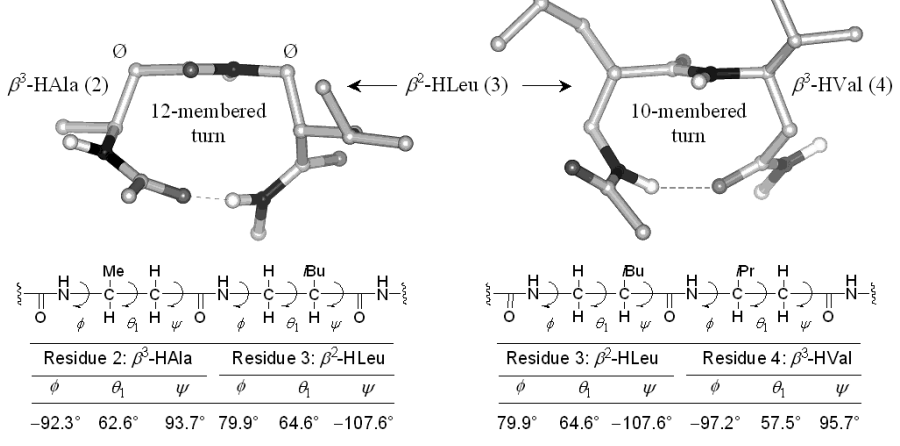

Fig. 2.10 The mixed $12 / 10$ helical structure of $\beta^{2} / \beta^{3}$-dipeptide repeats. (A) View along the helix axis of a low energy conformer resulting from NOE-restrained modeling of 14 in pyridine [144, 145]. (B) Comparison of the 12- and 10-membered turns found in the 12/10 helix of 14 together with corresponding backbone dihedral angles. 
tional N-terminal 10-membered turn and the pattern of 10- and 12-membered turns is reversed. The strong stabilizing effect associated with $\mathrm{N}$-terminus capping in mixed $\beta$-peptides was confirmed by $\mathrm{CD}$ studies in $\mathrm{MeOH}$, the ellipticity value at $205 \mathrm{~nm}$ for $15 \mathrm{in} \mathrm{MeOH}$ being twice that of 14. In the case of longer $\beta^{2} / \beta^{3}$-peptides, the effect of removing the terminal protecting groups was even more pronounced with collapse of the band at $205 \mathrm{~nm}$ and restoration of a CD pattern, albeit weak, characteristic of the $3_{14}$ helical conformation [145]. This observation may suggest the presence of equilibrating conformers and can be explained in term of unfavorable charge-pole interactions in the right-handed 12/ 10 -arrangement of unprotected $\beta^{2} / \beta^{3}$-peptides, the positively charged amino terminus being rather a promoter of left-handed 314 -helical structure. Information about the dynamic of (un)folding process in $\beta^{2} / \beta^{3}-\left(\beta^{3} / \beta^{2}-\right)$ dipeptide repeats (protected or unprotected form) was gained by exploration of conformational ensembles produced by molecular dynamics (MD) simulations in explicit solvent using the GROMOS96 force-field. The results demonstrated reversible folding to the 12/10 helix and were consistent with experimental data (see also Chapter 6). [103, 104, 149-151]. Although alternate conformations such as the pure lefthanded $33_{14}$-helix and various partially folded conformations were also populated, the right-handed 12/10 helix was the predominant conformation in the simulation of $\beta^{2} / \beta^{3}-\left(\beta^{3} / \beta^{2}\right.$-) dipeptide repeats in $\mathrm{MeOH}$.

\subsubsection{Additional Substitution Patterns Stabilizing the Mixed 10/12- (12/10-) Helix}

Theoretical studies at various levels of ab-initio $\mathrm{MO}$ theory $\left(\mathrm{HF} / 6-31 \mathrm{G}^{*}\right.$ and $\mathrm{B} 3 \mathrm{LYP} /$ $\left.6-31 \mathrm{G}^{*}\right)$ provided further insight into the relative preference of $\beta$-peptides for the $3_{14}$ and mixed 10/12-helices. Quantum mechanics calculations performed on unsubstituted $\beta$-peptides (oligo- $\beta$-HGly peptides) revealed that the formation of the 10/12-helix is intrinsically favored over the $33_{14}$ helix (by 21.4 and $4.8 \mathrm{kcal} \mathrm{mol}^{-1}$ in the gas phase and methanol solution for a protected hexapeptide) $[152,153]$. Analysis of the influence of substitution patterns $[151,154]$ confirmed the intrinsic preference of $(S)-\beta^{2} / \beta^{3}$ dipeptide repeats for the right-handed 10/12-helical conformation and suggested other patterns of substitutions compatible with the formation of the 10/12-helix such as heterochiral dipeptide repeats (e.g. $(R)-\beta^{3} /$ $\left.(S)-\beta^{3},(R)-\beta^{3} /(S)-\beta^{2},(S)-\beta^{2} /(R)-\beta^{2},(S)-\beta^{2} /(R)-\beta^{3}\right)$. This prediction was experimentally confirmed by the conformational analysis in solution of carbofuranosyl- $\beta^{3}$. hexapeptides 16 and 17 made of regularly alternating $(3 R)$ - and (3S)-building blocks (Fig. 2.9) [147].

In $\mathrm{MeOH}$, both peptides displayed a CD pattern characteristic of a right-handed 10/12- (12/10-) helical structure. More detailed structural analysis by NMR study in $\mathrm{CDCl}_{3}$ revealed that 16 and 17 adopt well-defined $(P)-12 / 10$ and 10/12 helical structures, respectively (Fig. 2.11).

It is noteworthy that the mixed $\beta$-peptide helical backbone can tolerate suppression of side chains every two residues. Thus, $\beta$-peptides made of alternating $(3 R)$ carbofuranosyl- $\beta^{3}$-amino acid and $\beta$-HGly (3-amino propionic acid) residues (18 and 19) and of $(2 \mathrm{~S}, 3 \mathrm{~S})-\beta^{2,3}$-(sugar) amino acid/ $\beta$-HGly repeats (20), respectively 
A

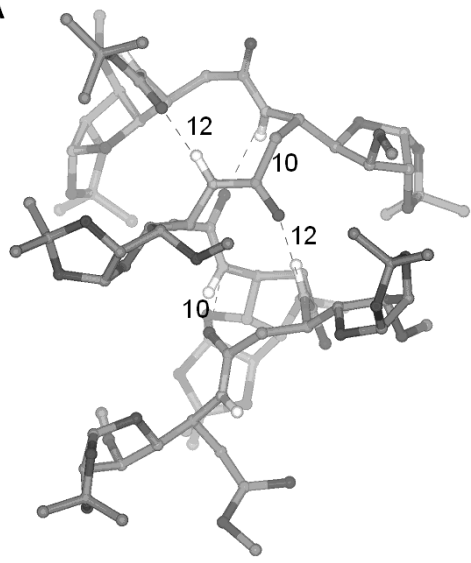

B

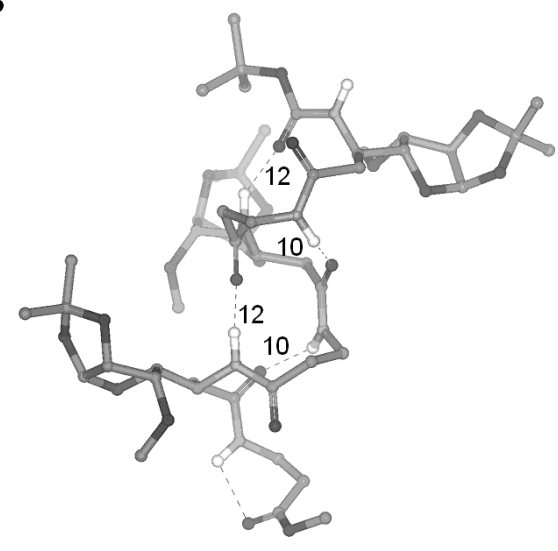

Fig. 2.11 Additional substitution patterns leading to mixed helices in $\beta$ peptides. Views along the helix axis of low energy conformers of (A) 16 and (B) 18 obtained by NOE-restrained modeling using NMR data obtained in $\mathrm{CDCl}_{3}[147,148]$.

have been found to adopt well-defined right-handed $(P)-12 / 10$ (18 and 20) and $(P)-10 / 12$ (19) helical structures in nonpolar solvents such as $\mathrm{CDCl}_{3}$ and $\mathrm{CD}_{3} \mathrm{CN}$ $[146,148]$. $\beta$-HGly thus behaves like $\beta^{2}$-amino acid residues in $\beta^{3} / \beta^{2}$ repeats. This finding is not surprising if one keeps in mind that $C(3)$ substitution is much more effective than $\mathrm{C}(2)$ in reducing the flexibility of the $\beta$-peptide backbone as already discussed in Section 2.3.1.1. Inverting the configuration of $\beta^{3}$ amino acid residues in $\beta^{3} / \beta$-HGly repeats $(\mathbf{1 8} \rightarrow \mathbf{2 1})$ caused a switch in helix handedness facilitated by the conformational freedom of $\beta$-HGly residues [148].

\subsection{3}

\section{Extending the Concept of Mixed Helices}

The question whether mixed helices might exist in other families of $\omega$-oligoamide backbones has been addressed by the group of Hofmann with methods of $a b$ initio theory $[153,154]$. Mixed helices were systematically searched within the conformational space of $\gamma$ - and $\delta$-peptides and their energies compared with those of corresponding periodic helices. The results indicate that (i) while mixed $\gamma$-peptide helices (14/12 and 24/22 H-bond pattern) are less stable than the experimentally found periodic 2.614 helix, mixed $\delta$-peptide helices (14/16 and 16/14 H-bond pattern) are significantly more stable according to the density functional theory (DFT) and (ii) in contrast to the situation observed for $\beta$-peptides, these mixed helices become more unstable than their periodic alternatives in polar environment such as water (polarizable continuum model, $\mathrm{PCM} / \mathrm{HF} / 6-31 \mathrm{G}^{*}$ ). These 

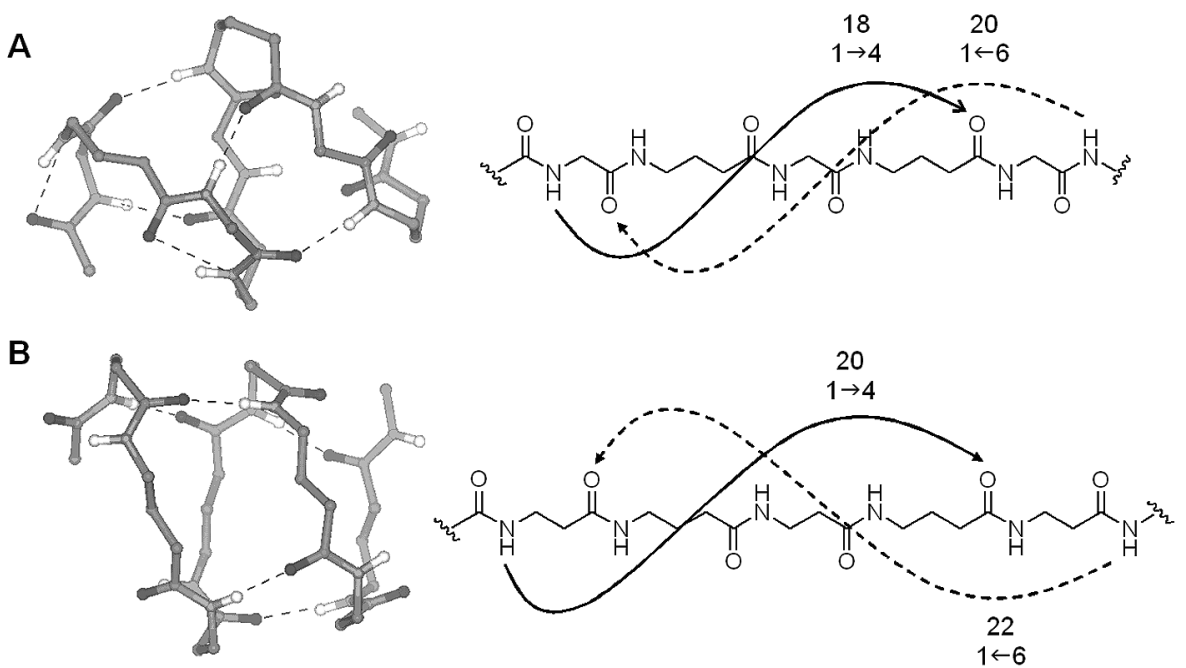

Fig. 2.12 Most stable helices in hybrid (octa)peptides at the HF/6-31G* level of $a b$ initio MO theory. (A) The mixed 18/20-helical fold of $\alpha, \gamma$ peptides, (B) the mixed 20/22-helical fold of $\beta, \gamma$-peptides [156].

mixed helical structures have not yet been observed experimentally in $\gamma$ - and $\delta$-peptides synthesized so far.

Another general approach to introduce periodicity at the level of a dimeric unit in oligoamides is to mix two types of $\omega$-amino acid residues in an alternating fashion. Such so-called heterogeneous or hybrid peptide backbones show considerable promise to expand the pool of candidate foldamers, and their experimental folding patterns are discussed with greater details in Section 2.6. Employing the methods of $a b$ initio MO theory, Hofmann and co-workers have investigated the ensembles of helical structures attainable with (unsubstituted) $\alpha, \beta$-, $\alpha, \gamma$ - and $\beta, \gamma$ hybrid backbones $[155,156]$. Conformational analysis provided three groups of helical structures according to their global $\mathrm{H}$-bonding pattern: helices with all $\mathrm{H}$ bonds in one direction (either forward or backwards direction), and mixed helices. For all three heterogeneous backbones, the most stable conformations at the $\mathrm{HF}$ and DFT level of $a b$ initio theory were found among mixed helices (i.e. 18/16(and 11/9-), 18/20- and 20/22-helical folds for $\alpha, \beta$-, $\alpha, \gamma$ - and $\beta, \gamma$-peptide hybrids, respectively, see Fig. 2.12). In an aqueous environment (PCM/HF/6-31G* calculations), the stability of helices with unidirectional $\mathrm{H}$-bonding increases at the expense of mixed helices. It is worth mentioning that some mixed helices such as the $11 / 9$-helix of $\alpha, \beta$-peptides remain significantly stable. Experimental evidence for the 11/9-helical fold came from NMR studies in $\mathrm{CDCl}_{3}$ of a series of $\alpha, \beta$ peptides consisting of L-Ala/(3S)-carbofuranosyl- $\beta^{3}$-amino acid repeat (e.g. 22 , See Fig. 2.13) [157]. 


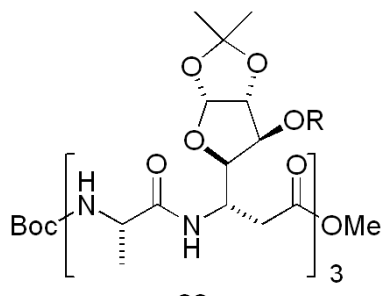

22

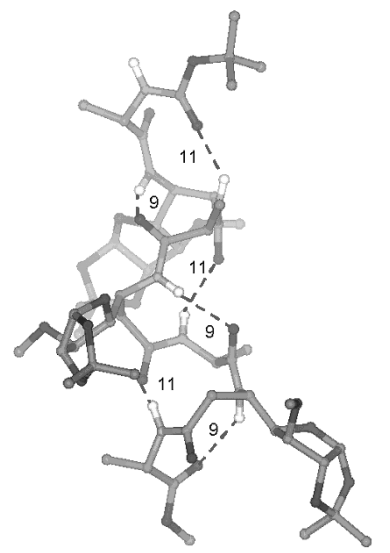

Fig. 2.13 The 9/11-Mixed helical structure of $\alpha / \beta$ hybrid peptides consisting of L-Ala/ (3S)-carbofuranosyl- $\beta^{3}$-amino acid repeats (e.g. 22). View along the helix axis of a low energy conformer of $\mathbf{2 2}$ generated by NOE-restrained modeling using NMR data obtained in $\mathrm{CDCl}_{3}$ [157].

\section{5}

Nonperiodic Structures: Open Chain $\beta$-Turn-like Motifs and Hairpins in Designed Homo-oligomers

Turn structures and $\beta$-hairpins (two H-bonded antiparallel $\beta$-strands connected by a turn segment) which cause the peptide chain to reverse its direction are key functional and structural elements of proteins. Significant progress has been made towards our understanding of the principles that govern $\beta$-hairpin nucleation (for reviews, see refs [8-10] and Chapter 5). Because these motifs are important for peptide and protein recognition, the design, synthesis and applications of hairpin turn mimetics have attracted considerable attention. In the foldamer area, the de novo design of hairpin-type structures from unnatural linear oligomers remains challenging, in part because of the duality of structural elements (turn + sheet) and the absence of periodicity in the motif. So far, homooligomers (based on one residue type) programmed to adopt hairpin conformations have been essentially limited to $\beta$-peptides. Alternatively, the individual components of hairpin design (i.e. either turn segments or pleated sheet structures) generated from various unnatural oligomeric backbones (e.g. $\beta$ - and $\gamma$ peptides, $\alpha$-aminoxy acid oligomers) can be assembled with $\alpha$-peptide strands or $\beta$-turn segments to generate hybrid hairpin structures (see Section 2.6.2).

\subsection{1}

\section{Sheet-forming $\omega$-peptides}

Fully extended $\beta$-peptide strands can be generated by populating antiperiplanar conformations around the $\mathrm{C}(\alpha)-\mathrm{C}(\beta)$ bond $\left(\theta_{1}\right.$ values close to $\left.180^{\circ}\right)$. Seebach and 
Gellman groups found that this conformational bias can be introduced by using acyclic $\beta^{2,3}$-amino acids of unlike configuration bearing alkyl substituents [158, 159]. The resulting $\beta^{2,3}$-peptide chains adopt extended conformation with formation of pleated sheets. This is in contrast to all-like- $\beta^{2,3}$-peptides which have be shown to form predominantly 314 helical structures (See Section 2.3.1). Extended conformations for sheet formation are also accessible to $\gamma$-peptides subject to sufficient backbone pre-organization $(\alpha, \beta$-unsaturation [160], cyclization between $\mathrm{C}(\alpha)$ and $\mathrm{C}(\gamma)[161])$ to restrict rotation around ethylene bond.

\subsection{2}

\section{Turn Segment for Hairpin Formation}

Two types of $\beta$-dipeptide turn segments have been used to connect antiparallel $\beta$ peptide strands and nucleate $\beta$-peptide hairpin conformations.

The first one imagined by Gellman and his group is a 12-membered H-bonded turn generated by a heterochiral dinipecotic acid (Nip, the $\beta^{2}$-homolog of proline: $\beta^{2}$-HPro) sequence $[162,163]$. X-ray crystal structure of a designed $\beta$-tetrapeptide (23, Fig. 2.14A) show the expected antiparallel hairpin conformation, all strand residues displaying antiperiplanar arrangement around the $C(\alpha)-C(\beta)$ bond [162]. The second approach developed by Seebach and co-workers (24, Fig. 2.14B) exploits the propensity of mixed $\beta^{2} / \beta^{3}$-dipeptides to populate 10 -membered $\mathrm{H}$ bonded turn (see Section 2.4.2.1 and Fig. 2.10) [159, 164]. Detailed NMR spectroscopy and MD simulation analysis of $\beta$-hexapeptide 24 in $\mathrm{CD}_{3} \mathrm{OH}$ revealed significant (an estimation of $20-30 \%$ was given by MD) hairpin population. There was however no evidence for secondary structure in water. The structural similarity between the 10-membered turn segment in 24 and a type II' $\alpha$-peptide $\beta$-turn is illustrated in Fig. 2.14E. Interestingly, the formation of $\beta$-peptide 10 -membered H-bonded turns was also found to be strongly promoted by $\beta^{2,2}$-geminally substituted amino acids units such as achiral 1-aminomethylcyclohexanecarboxylic acid [51]. The hairpin structures in both 23 and 24 are characterized by the unidirectionality of the $\mathrm{C}=\mathrm{O}$ and $\mathrm{NH}$ bonds within each strand segment. However, as a consequence of their different turn geometry: a 12-membered turn closed by H-bonds between $\mathrm{C}=\mathrm{O}_{i}$ and $\mathrm{NH}_{i+3}$, and a 10-membered turn closed by $\mathrm{H}$-bonds between $\mathrm{NH}_{i}$ and $\mathrm{C}=\mathrm{O}_{i+1}$, antiparallel hairpins formed by $\beta$-peptides 23 and 24 display opposite sheet polarities. Backbone torsion angle values (X-ray and NMR) for selected $\beta$-amino acids residues within extended strand segments of 23 and 24 are close to ideal values for $\beta$-peptide pleated sheets: $\phi=-120^{\circ}$ (or $120^{\circ}$ ), $\theta_{1}=$ $180^{\circ}, \psi=120^{\circ}\left(\right.$ or $\left.-120^{\circ}\right)$.

Optimal pre-organization of the $\gamma$-peptide backbone towards the formation of open-chain turn-like motifs was found to be promoted by unlike- $\gamma^{2,4}$-amino acid residues [165-166]. This design principle can be rationalized by examination of the two conformers free of syn-pentane interaction (I and II, Fig. 2.14C). $\gamma^{2,4}$. peptides built from either homochiral or heterochiral unlike- $\gamma^{2,4}$-amino acid units adopt reverse turn-like structure stabilized by 14-membered $\mathrm{H}$ bond (e.g. 25, Fig. 2.14D). $\gamma$-Peptide turn conformations compare well with the type $\mathrm{II}^{\prime} \beta$-hairpin 
$60 \mid 2$ Foldamers Based on Remote Intrastrand Interactions

A

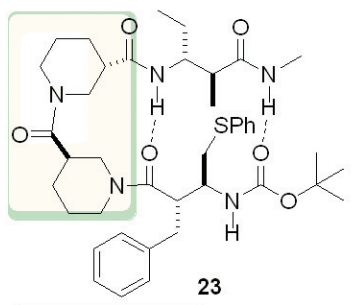

B

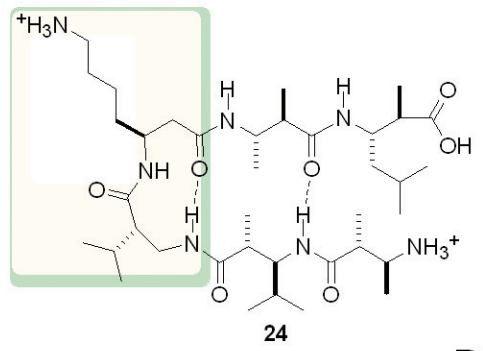

C

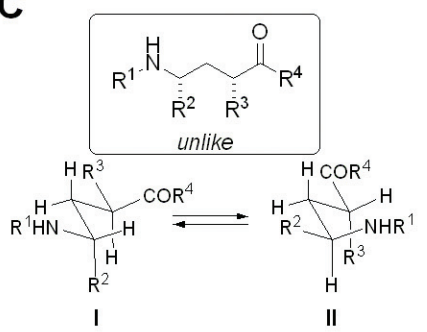

E

10-membered turn segment in $\mathbf{2 4}$

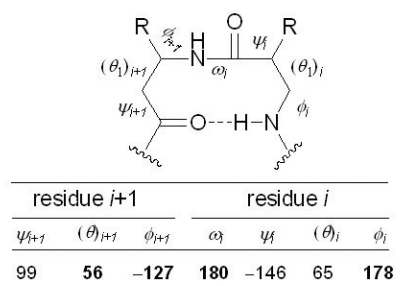

D
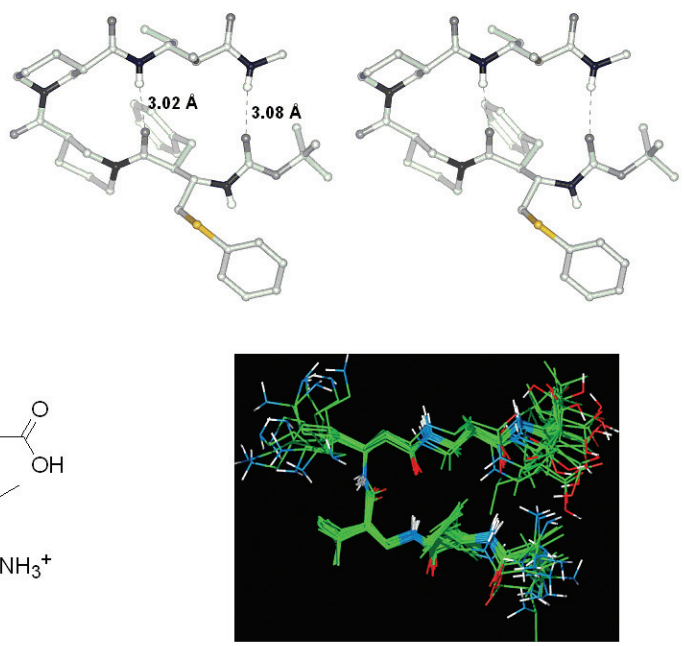<smiles>CNC(=O)[C@H](C)CC(NC(=O)[C@H](Cc1ccccc1)CC(C)NC(C)=O)C(C)C</smiles>

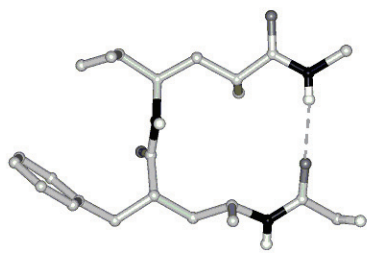

14-membered ring of a

10-membered ring of a type II' $\beta$-turn

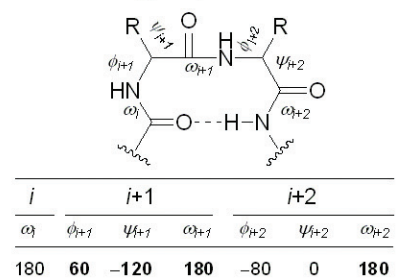
type II' $\beta$-turn in 25

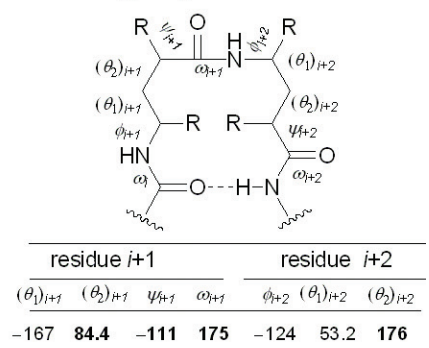

Fig. 2.14 Nonperiodic structures formed by $\beta$ - and $\gamma$-peptides. $\beta$-peptide antiparallel hairpin structures with (A) a 12-membered $R / S$ dinipecotic turn segment (e.g. 23, X-ray structure) [162] and (B) with the 10membered turn formed by mixed $\beta^{2} / \beta^{3}$. dipeptide sequence (e.g. 24, structure derived from NMR data in $\mathrm{CD}_{3} \mathrm{OH}$ ) [164]. (C) The two conformation free of destabilizing synpentane interaction in $\gamma^{2,4}$-amino acid with unlike configuration. (D) 14-membered $\mathrm{H}$ - bonded turn induced by $\gamma$-peptides consisting of unlike- $\gamma^{2,4}$-amino acid residues (heterochiral sequence) (e.g. 25, X-ray structure) [166]. (E) Comparison of the turn segment found in $\beta$ - and $\gamma$-peptide 24 and 25 with a naturally occuring type $\mathrm{II}^{\prime} \beta$-turn of $\alpha$-polypeptides together with backbone dihedral angles in $\left({ }^{\circ}\right)$. Torsion angles with comparable values are shown in bold [164, 166]. 
motif of naturally occurring $\alpha$-peptides, thus suggesting that short-chain $\gamma$ peptides with the right substitution pattern could be used as $\beta$-turn mimetics in drug design.

\section{6}

\section{Expanding Structural Diversity with Heterogeneous Backbones}

Most structural motifs encountered in the previous sections of this chapter have been generated from oligomeric strands formed by the repeat of monomeric units from a single class. While the design of appropriate building blocks for the construction of homogeneous folding oligomers based on remote intrastrand interactions remains an active area, the possibility to combine these elements and generate new heterogeneous backbones as candidate foldamers has recently emerged. This concept, successfully applied to oligoamides, spectacularly expands the structure space attainable with a relatively small pool of residue types.

\subsection{1}

\section{From Discrete $\omega$-Amino Acid Guests in $\alpha$-Helices to Helical $\alpha, \omega$ - and $\beta, \gamma$-Peptide Hybrids}

Multiple approaches, either experimental [167-172] or theoretical [155, 156], have been considered to delineate the ensemble of helical conformations formed by new hybrid backbones composed of two $\omega$-amino acid residue types. Oligomers with periodicity at the level of dimer (e.g. $\alpha, \beta-, \alpha, \gamma-, \beta, \gamma$-peptides) or trimer (e.g. $\alpha, \alpha, \beta$ - or $\alpha, \beta, \beta$-peptides) units have been studied.

For several years, Balaram and co-workers have been investigated the structural features of $\beta$ - and $\gamma$-amino acid residues ( $\beta$-HGly, $\gamma$-Gly (4-aminobutyric acid), Gpn (gabapentin)) when inserted as guests into host $\alpha$-peptides [173]. Examination of X-ray crystal structures of peptides 26-28 [172, 174, 175] (see Table 2.1

Table 2.1 Residue patterns (in bold) within peptides 26-28 whose coordinates served to construct models of hybrid helices.

\begin{tabular}{|c|c|c|c|c|}
\hline & Sequence & Pattern & $\begin{array}{l}\text { Number } \\
\text { of atoms in } \\
\text { H-bonded ring }\end{array}$ & Ref \\
\hline 26 & $\begin{array}{l}\text { Boc-Val-Ala-Phe-Aib- } \beta^{3} \text {-HVal- } \boldsymbol{\beta}^{3} \text {-HPhe-Aib-Val-Ala-Phe-Aib-OMe } \\
\text { Boc-Val-Ala-Phe-Aib- } \boldsymbol{\beta}^{3} \text {-HVal- } \boldsymbol{\beta}^{3} \text {-HPhe-Aib-Val-Ala-Phe-Aib-OMe }\end{array}$ & $\begin{array}{l}\beta \alpha \\
\alpha \beta \beta\end{array}$ & $\begin{array}{l}11 \\
15\end{array}$ & 175 \\
\hline 27 & Boc-Leu-Phe-Val-Aib- $\boldsymbol{\beta}^{3}$-HPhe-Leu-Phe-Val-OMe & $\alpha \alpha \beta$ & 14 & 172 \\
\hline 28 & $\begin{array}{l}\text { Boc-Leu-Aib-Val- } \beta \text {-HGly- } \boldsymbol{\gamma} \text {-Gly-Leu-Aib-Val-Ala-Leu-Aib-OMe } \\
\text { Boc-Leu-Aib-Val- } \boldsymbol{\beta} \text {-HGly- } \boldsymbol{\gamma} \text {-Gly-Leu-Aib-Val-Ala-Leu-Aib-OMe }\end{array}$ & $\begin{array}{l}\gamma \alpha \\
\beta \gamma\end{array}$ & $\begin{array}{l}12 \\
13\end{array}$ & 174 \\
\hline
\end{tabular}


for sequences) revealed that $\beta$ - and $\gamma$-amino acid residues can be substituted for their $\alpha$-amino acid counterpart at discrete position in $\alpha$-helical structures without major perturbation of the overall fold.

Experimentally defined backbone torsion angles of expanded $1 \leftarrow 4$ and $1 \leftarrow 5$ $\mathrm{H}$-bonded units formed by hybrid segments in these peptides (marked in bold in Table 2.1) served as starting points to generate a series of energetically favorable models of $\alpha, \omega$-hybrid helices. For example, the 11- and 13-membered H-bonded units encompassing the $\beta^{3}$-HPhe-Aib $(\beta, \alpha)$ and the $\beta$-HGly- $\gamma$-Gly $(\beta, \gamma)$ segments in X-ray structure of 26 [175] and 28 [174] provided appropriate geometrical parameters to model $11-\beta, \alpha$ and $13-\beta, \gamma$-helices. It is worth noting that a $\beta, \gamma$-dipeptide repeat is isostere to a $\alpha$-tripeptide and that the 13-helical backbone proposed for $\beta, \gamma$-peptides $\left(\phi=-106^{\circ}, \theta=75^{\circ}, \psi=-115^{\circ}\left(\beta^{3}\right.\right.$-amino acid $)$ and $\phi=-117^{\circ}$, $\theta_{1}=66^{\circ}, \theta_{2}=62^{\circ}, \psi=-120^{\circ}(\gamma$-amino acid $)$ ), and also identified by quantum mechanics calculations [156] superimposes well to the $\alpha$-helical backbone (RMSD value of $0.7 \AA$ ). This interesting theoretical consideration will need to be verified experimentally.

Parallel to these semi-empirical studies, Reiser, Zerbe and colleagues [167] and Gellman [168-171] independently reported experimental evidence for periodic helix formation in short chain hybrid peptides consisting of alternating $\alpha$ - and $\beta$ amino acid residues (mixed helices reported by Sharma and Kunwar [157] have already been discussed in Section 2.4.3). In both cases, backbone pre-organization to enforce folding propensity was introduced at the $\beta$-amino acid positions with 2aminocycloalkanecarboxylic acid residues. $\alpha, \beta$-Peptides designed by Gellman and co-workers contained $\beta$-amino acid residues constrained with five-membered rings (S,S)-trans-ACPC and (S,S)-trans-APC (e.g. 29 and 30, Fig. 2.15).

Detailed NMR analysis of hybrid peptide 29 in $\mathrm{CD}_{3} \mathrm{OH}$ revealed a complex pattern of $(i, i+2)$ and $(i, i+3)$ inter-residue NOE connectivities that could be explained by assuming rapid interconversion between two helical conformations with $\mathrm{H}$ bonds in backward direction, namely a 11-helix $(1 \leftarrow 4 \mathrm{H}$ bonds) and a 14/15-helix ( $1 \leftarrow 5 \mathrm{H}$ bonds) [168]. Although less plausible, a helical conformation with three-center backbone $\mathrm{H}$ bonds (both 11- and 14/15 H-bonded rings) was also proposed on the basis of the nonsequential NOEs observed. Factors governing helical folding propensity and helix type repartition in such $\alpha, \beta$-peptide hybrids have been delineated. Increase in chain length seems to favor the 14/15 helical shape relative to the 11-helix [168]. The analogy to $\alpha$-peptides which also show chain length-dependent conformational transition between $3_{10}$ helix ( $1 \leftarrow 4 \mathrm{H}$ bonds) and $\alpha$-helix ( $1 \leftarrow 5 \mathrm{H}$-bonding pattern) is striking (Fig. 2.16).

$\alpha, \alpha$-Disubstitution of $\alpha$-amino acids which is well known to promote helical folding among $\alpha$-peptides [15] was shown to reinforce helix stability and to favor 11-helical folding of $\alpha, \beta$-peptide hybrids [170]. Octamer 30 which consists of ACPC/Aib repeats adopts a perfect 11-helical fold in the solid state with all possible $\mathrm{H}$-bonded rings present (Fig. 2.17A). In contrast, $\beta$ substitution of $\alpha$ aminoacid residues (e.g. Val, Ile, Thr) or substitution of acyclic $\beta$-amino acids for ACPC/APC residues is helix destabilizing [170]. Pre-organization with sixmembered ring $(S, S)$-trans-ACHC residues does not support helix formation in 


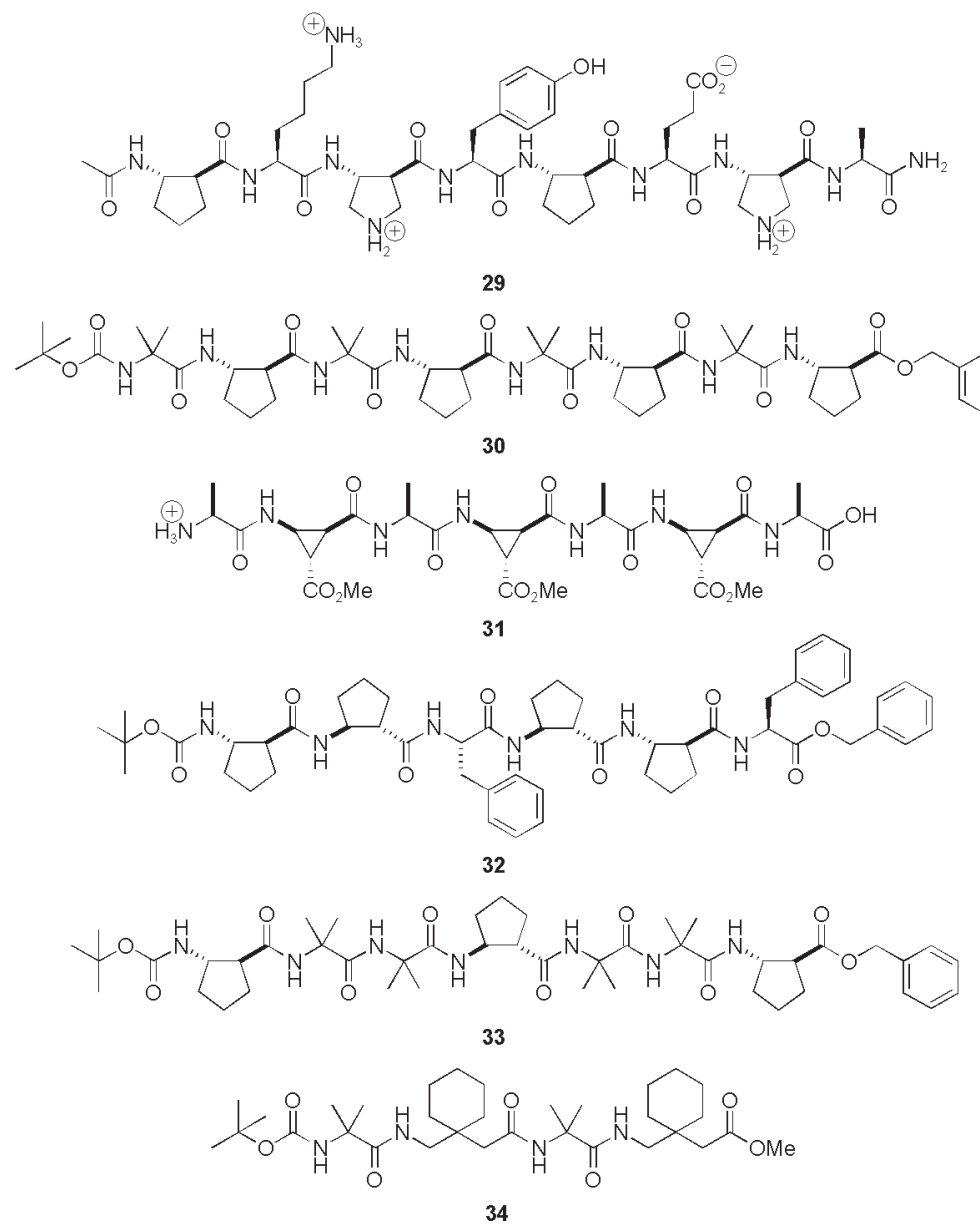

Fig. 2.15 Helix forming $\alpha, \omega$-peptide hybrids [167-172].

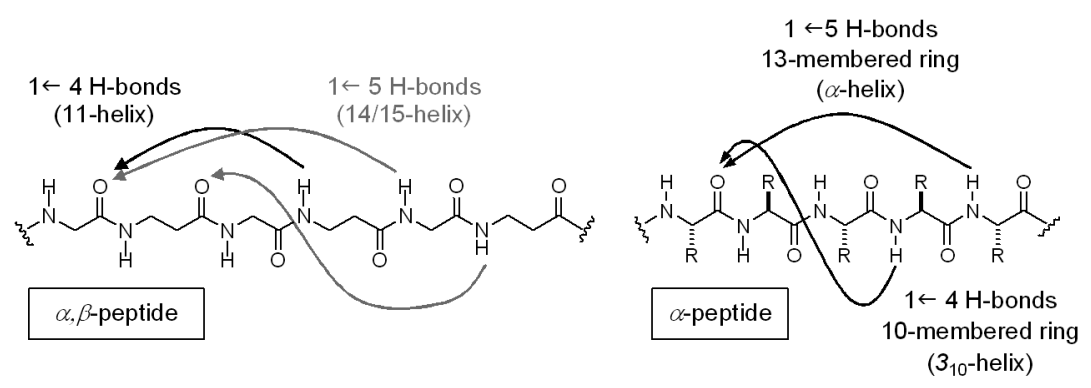

Fig. $2.161 \leftarrow 4$ and $1 \leftarrow 5 \mathrm{H}$-bond patterns of interconverting 11- and $14 / 15$-helices in heterogeneous $\alpha, \beta$-peptides such as 29 and analogy with $\mathrm{H}$-bonding scheme of $3_{10}$ and $\alpha$-helical secondary structures. 
A
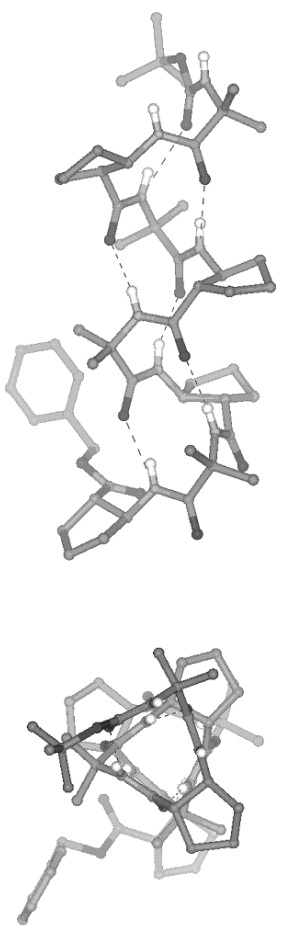

B
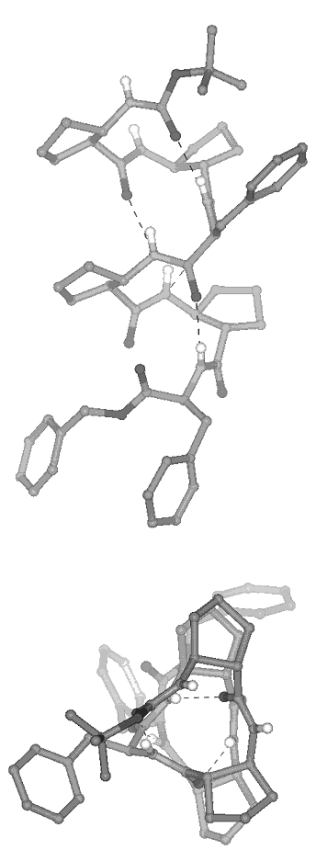

C
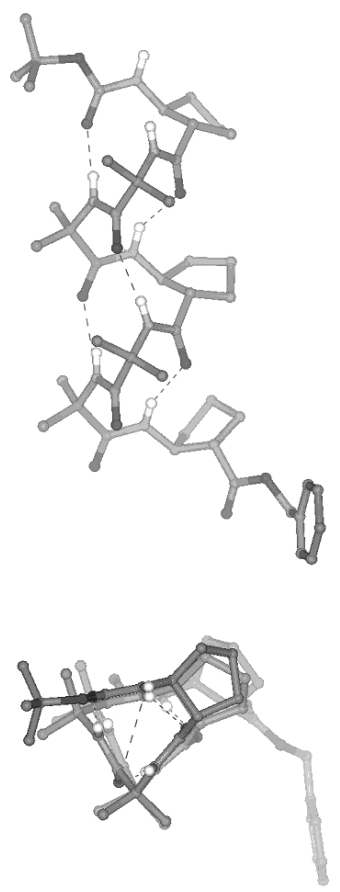

Fig. 2.17 Helical secondary structures of peptide hybrids in the solid state (views along the helix axis and top views). (A) Right handed 11-helix formed by $\alpha, \beta$-peptide 30 (adapted from [170]). The backbone torsion angles extracted for central residues 4 and 5 $\left(\phi=-99.7^{\circ}, \theta=89.6^{\circ}, \psi=-80.7^{\circ}(\beta\right.$ amino acid) and $\phi=-50.3^{\circ}, \psi=-42.9^{\circ}$ $(\alpha$-amino acid $))$ and those derived from the computer-generated model proposed by
Balaram $\left(\phi=-105^{\circ}, \theta=80^{\circ}, \psi=-73^{\circ}\right.$ $\left(\beta\right.$-amino acid) and $\phi=-62^{\circ}, \psi=-44^{\circ}$ ( $\alpha$-amino acid) [172]) are in good agreement. (B) Right handed helical conformation ( $1 \leftarrow 4 \mathrm{H}$-bonding pattern) of $\alpha, \beta, \beta$-peptide 32 (adapted from [171]). (C) Right handed helical conformation $(1 \leftarrow 4 \mathrm{H}$-bonding pattern) of $\alpha, \alpha, \beta$-peptide 33 (adapted from [171]).

$\alpha / \beta$-peptide hybrids, probably because homogenous ACHC backbones favor $\mathrm{H}$ bonding in the forward direction (see Section 2.3.1.2) [168].

In a related work [167], Reiser, Zerbe and colleagues used cis- $\beta$-aminocyclopropanecarboxylic acids (cis- $\beta$-ACCs) substituted on the 3-position of the ring and investigated oligomers consisting of $\mathrm{L}-\mathrm{Ala} / \mathrm{cis}-\beta$-ACC repeats (exemplified by heptamer 31). NMR studies in $\mathrm{CD}_{3} \mathrm{OH}$ and molecular modeling calculations led to the identification of a third helical fold (with $1 \leftarrow 3 \mathrm{H}$-bonds) for $\alpha, \beta$-peptide hybrids.

Introducing periodicity at the level of a trimer unit with $\beta, \beta, \alpha$ - and $\beta, \alpha, \alpha$-triad repeats (hexamer 32 and heptamer 33) successfully led to the identification of new helical secondary structures (Fig. 2.17B and C) [171]. While X-ray diffraction 
studies led to the characterization of helices with $1 \leftarrow 4 \mathrm{H}$ bonds, evidence for rapid interconversion between two helical conformations $(1 \leftarrow 4$ and $1 \leftarrow 5 \mathrm{H}$ bonding patterns) was gained from NMR studies in $\mathrm{CD}_{3} \mathrm{OH}$.

Experimental evidence that short chain $\alpha, \gamma$-peptide hybrids also adopt helical secondary structures came from X-ray diffraction studies of tetramer 34 consisting of Aib-Gpn repeats [172]. The observed helical fold is stabilized by $12 \mathrm{H}$ bonds in the backwards direction. By fixing both ethane bonds in a synclinal conformation (values for both $\theta_{1}$ and $\theta_{2}$ are close to $60^{\circ}$ ), $\beta, \beta$-disusbtitution (in $\mathrm{Gpn}$ ) ensures conformational space restriction of $\gamma$-amino acid residues.

\subsection{2}

\section{Hairpins from $\alpha, \omega$-Peptide Hybrids}

New hairpin type motifs have been generated by combining turn and strand segments made of distinct backbones (Fig. 2.18).

D-Pro-Xaa and Asn-Gly dipeptide sequences are known to support the formation of type $\mathrm{I}^{\prime}$ or II $^{\prime} \beta$-turns and to promote nucleation of $\alpha$-peptide hairpin structures [176-178]. By extension, the D-Pro-Gly turn motif [179] or a related depsipeptide segment L-Pro-glycolate [158] have been used to connect $\beta$-peptide

A<smiles>COC(=O)CC(Cc1ccccc1)N(Cc1ccccc1)C(=O)CC(Cc1ccccc1)NC(=O)C[C@H](CCC(=O)N1CCC[C@H]1C(=O)NCC(=O)OC(C)(C)C)NC(=O)OC</smiles>

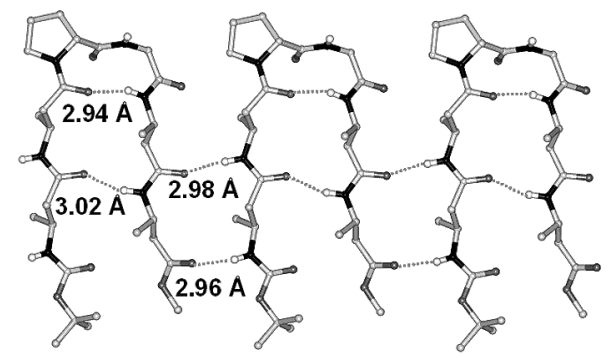

B

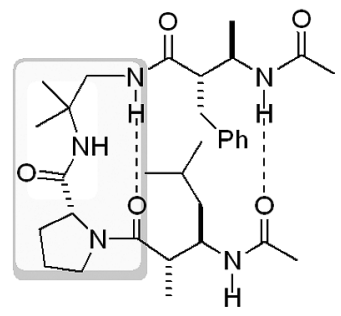

36

C

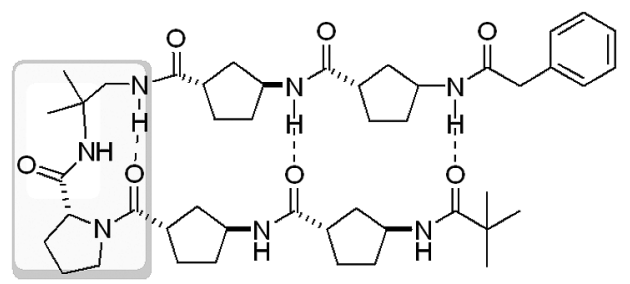

37

Fig. 2.18 (A) Hybrid $\beta$-peptide 35 with a D-Pro-Gly type II' $\beta$-turn segment (grey color): X-ray crystal structure [179]. Intermolecular $\mathrm{NH} \cdots \mathrm{O}=\mathrm{C} \mathrm{H}$ bonds (with $\mathrm{N}-\mathrm{H} \cdots \mathrm{O}$ ) angles of $160^{\circ}$ and $133^{\circ}$ ) connect the hairpin into an infinitely extended $\beta$-sheet. (B, C) Parallel hairpin formation in $\beta$ - and $\gamma$-peptides (e.g. 36, 37) by incorporation of a D-ProDADME turn segment $[158,183]$. 
strands into new antiparallel hairpin type structures (e.g. 35). X-ray diffraction studies have shown that $\beta$-amino acids residues generally adopt the expected antiperiplanar conformation around the ethylene bond $\left(\theta \sim 180^{\circ}\right)$. The same holds true for $\beta$-hairpins obtained by incorporation of $\beta$ - or $\gamma$-amino acids at discrete positions into the strand segments $\left(\theta_{1}\right.$ and $\theta_{2}$ values $\left.\sim 180^{\circ}\right)$ [180-182]. Specific connectors made of several residue types such as D-Pro-(1,1-dimethyl)-1,2diaminoethyl (D-Pro-DADME) have been reported that allow formation of parallel hairpin type structures from $\beta$ - (e.g. 36) and $\gamma$-peptides (made of constrained trans-3-ACPC residues, e.g. 37) strand segments [158, 183]. Conversely, studies by the groups of Gellman and Yang have shown that $\beta$-peptides (dinipecotic acid heterochiral sequence, see Section 2.5) [184] and $\alpha$-aminoxy-peptides (D,L- $\alpha$ aminoxy acid dimer) [116] reverse turn segments can be used to nucleate $\alpha$ peptide hairpin structures.

\subsection{3}

\section{Sculpting New Shapes by Integrating H-Bonding, Aromatic Interactions and Multiple Levels of Pre-organization}

As outlined in the previous sections, optimal backbone pre-organization for the formation of $\mathrm{H}$ bonds and stabilization of well-defined secondary structures (helices and hairpin type structure) has been achieved at an unprecedented level for a whole series of aliphatic oligoamides and related peptidomimetic oligomers. The design principles applied to homogeneous backbones have been extended successfully to heterogeneous backbones. Recent studies with aromatic oligoamides suggest that it is possible to design oligomeric sequences coding for more complex structural information. Hunter and Thomas have shown that 38, a $C_{2}$ symmetric strand built of isophthalic acid, bisaniline and 4-nitro- $1 \mathrm{H}$-pyrrole-2carboxylic acid residues adopt in nonpolar solvent $\left(\mathrm{CDCl}_{3}\right)$ a well defined and unusual fold, stabilized by a combination of H-bonding and aromatic interactions between non-nearest neighbors (Fig. 2.19A) [185].

Experimentally measured folding-induced changes in ${ }^{1} \mathrm{H}$-NMR chemical shift $(\Delta \delta)[186]$ compared with unfolded reference compounds were used to calculate the three dimensional structure of this "tailbiter". Experimental H-D exchange data reflect the difference of free energy in $\mathrm{CDCl}_{3}$ between the $\mathrm{H}$-bonds at work, pyrrole-amide $\left(\sim 6 \mathrm{~kJ} \mathrm{~mol}^{-1}\right)$ versus amide-nitro $\left(\sim 2 \mathrm{~kJ} \mathrm{~mol}^{-1}\right) \mathrm{H}$-bonds $)$ and support a noncooperative unfolding mechanism. Self-organization properties of related aromatic oligoamides composed of isophthalic acid, and bisaniline units in nonpolar solvents have been exploited for the synthesis of a whole series of supramolecular entities $[187,188]$, including molecular trefoil knots $[189,190]$. Folding of oligoamide $\mathbf{4 1}$ - which has been proposed to be formed transiently upon reaction of diamine 39 with 2,6-pyridinedicarboxylic acid dichloride 40 - into a helical loop stabilized by a complex collection of intrastrand H-bonding (both remote and between nearest neighbors) and aromatic interaction is thought to be an early and critical event prior to self-threading and successful closing to amide-knot 42 (Fig. 2.19B). 


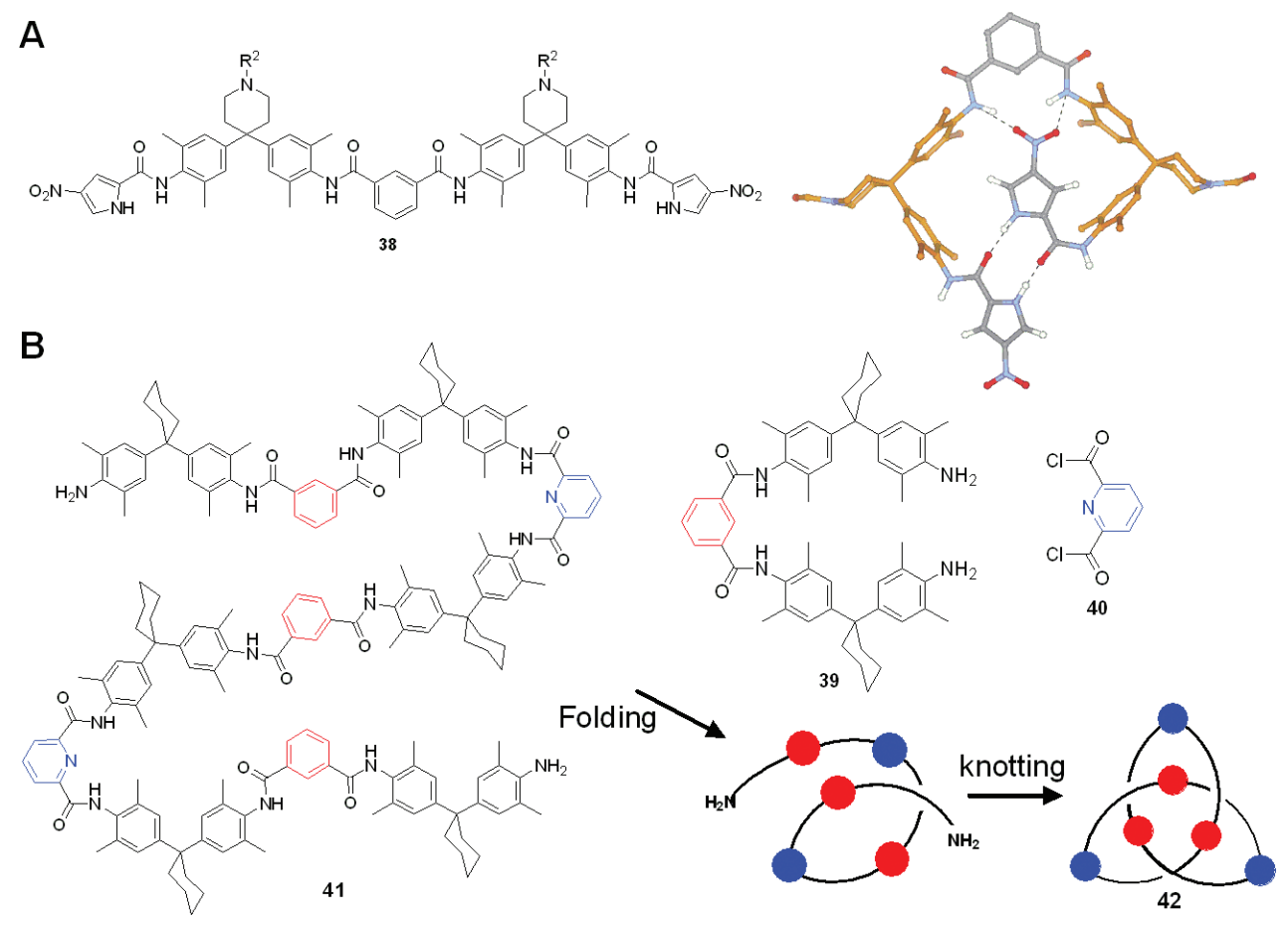

Fig. 2.19 Aromatic oligoamide foldamers (A) "Tailbiter" 38 [185]; (B)

Proposed folding mechanism for the formation of amide knot 42 [189].

\section{7}

\section{Conclusion and Outlook}

The "homologation strategy" which initially led to the discovery of the robust 14-helical $\beta$-peptide backbone gave a strong impetus to the search of new foldamers stabilized by remote intrastrand interactions. In 10 years, the number of different secondary structures accessible from $\beta$-peptides and higher homologs of $\alpha$-polypeptides has grown steadily and the basic principles underlying $\omega$-peptide folding have been delineated. Multiple levels of conformational restriction can be applied to $\omega$-amino acid units to pre-organize the oligoamide backbone for folding. For instance, the insertion of heteroatoms into the backbone of $\omega$-peptides to restrict the conformational space results in nonpeptide strands with unique folding patterns. Furthermore, mixing building blocks of more than one type to generate foldamers with hybrid backbones has recently emerged as a promising concept to explore further the structure space attainable with a relatively small set of building units. Although potentially informative, a comparative study of these bioinspired foldamers is not straightforward. Several important issues such as (i) the predictability of folding; (ii) the mechanisms of folding/unfolding; (iii) the ef- 
fect of environment on folding; (iv) the chain-length dependence and (v) the conversion of structure into function which have been addressed thoroughly in the case of $\beta$-peptides, still need to be considered for many oligomers with folding propensity. Despite some success in the formation of supersecondary structures from $\beta$-peptides (helix bundles and hairpin), a major challenge will be the assembly of foldamer secondary/supersecondary structures into more complex proteinlike tertiary structures (tyligomers). Nonetheless, significant progress continues with regards to the design of foldamers with functions (e.g. in biology, see Chapter 8) and one foresees a bright future for folding oligomers based on remote intrastrand interactions.

\section{Acknowledgments}

We are grateful to the Centre Nationale de la Recherche Scientifique (CNRS), the Agence Nationale pour la Recherche (ANR), the Région Alsace and ImmuPharma France for research support.

\section{References}

1 Appella, L. A. Christianson, I. L. Karle, D. R. Powell, S. H. Gellman, J. Am. Chem. Soc. 1996, 118, 1307113072.

2 S. H. Gellman, Acc. Chem. Res. 1998, 31, 173-180.

3 D. Seebach, M. Overhand, F. N. M. Kühnle, B. Martinoni, L. Oberer, U. Hommel, H. Widmer, Helv. Chim. Acta 1996, 79, 913-941.

4 D. Seebach, J. L. Matthews, Chem. Commun. 1997, 2015-2022.

5 J. Venkatraman, S. C. Shankaramma, P. Balaram, Chem. Rev. 2001, 101, 3131-3152.

6 W. F. DeGrado, C. M. Summa, V. Pavone, F. Nastri, A. Lombardi, Annu. Rev. Biochem. 1999, 68, 779-819.

7 M. J. I. Andrews, A. B. Tabor, Tetrahedron, 1999, 55, 11711-11743.

8 E. Lacroix, T. Kortemme, M. Lopez de la Paz, L. Serrano, Curr. Opin. Struct. Biol. 1999, 4, 487-493.

9 S. H. Gellman, Curr. Opin. Chem. Biol. 1998, 2, 717-725.

10 G. D. Rose, L. M. Gierasch, J. A. Smith, Adv. Prot. Chem. 1985, 37, 1-110.
11 G. Quinkert, E. Egert, C. Griesinger, Macromolecular and Supramolecular Chemistry in Aspects of Organic Chemistry, Structure, G. Quinkert, E. Egert, C. Griesinger (Eds.), Verlag Helvetica Chimica Acta, Basel, 1996.

12 A. Chakrabartty, R. L. Baldwin, Adv. Prot. Chem. 1995, 46, 141-176.

13 A. G. Street, S. L. Mayo, Proc. Natl. Acad. Sci. USA 1999, 96, 9074-9076.

14 D. L. Jr Minor, P. S. Kim, Nature 1994, 367, 660-663.

15 C. Toniolo, M. Crisma, F. Formaggio, C. Peggion, Biopolymers (Pept. Sci.) 2001, 60, 396-419.

16 R. Fairman, K. R. Shoemaker, E. J. York, J. Stewart, R. L. Baldwin, Proteins: Struct. Funct. Genet. 1989, 5 , 1-7.

17 S. Marqusee, R. L. Baldwin, Proc. Natl. Acad. Sci. USA 1987, 84, 8898-8902.

18 C. A. Olson, Z. Shi, N. R. Kallenbach, J. Am. Chem. Soc. 2001, 123, 64516452.

19 C. D. Andrew, S. Bhattacharjee, N. Kokkoni, J. D. Hirst, G. R. Jones, A. J. Doig, J. Am. Chem. Soc. 2002, 124, 12706-12714. 
20 F. Ruan, Y. Chen, P. B. Hopkins, J. Am. Chem. Soc. 1990, 112, $9403-$ 9404.

21 M. R. Ghadiri, C. Choi, J. Am. Chem. Soc. 1990, 112, 1630-1632.

22 D. Y. Jackson, D. S. King, J. Chmielewski, S. Singh, P. G. Schultz, J. Am. Chem. Soc. 1991, 113, 93919392.

23 J. W. Taylor, Biopolymers 2002, 66, 49-75.

24 H. E. Blackwell, R. H. Grubbs, Angew. Chem. Int. Ed. 1998, 37, 3281-3284.

25 L. D. Walensky, A. L. Kung, I. Escher, T. J. Malia, S. Barbuto, R. D. Wright, G. Wagner, G. L. Verdine, S. J. Korsmeyer, Science 2004, 305, 14661470.

26 A. Banerjee, P. Balaram, Curr. Science 1997, 73, 1067-1077.

27 D. J. Hill, M. J. Mio, R. B. Prince, T. S. Hughes, J. S. Moore, Chem. Rev. 2001, 101, 3893-4011.

28 R. P. Cheng, S. H. Gellman, W. F. DeGrado, Chem. Rev. 2001, 101, 3219-3232.

29 T. A. Martinek, F. Fülop, Eur. J. Biochem. 2003, 270, 3657-3666.

30 G. Guichard. In Pseudopeptides in Drug Development; Nielsen, P. E., Ed.; Wiley-VCH Verlag: Weinheim, Germany, 2004; 33-120.

31 D. Seebach, A. K. Beck, D. J. Bierbaum, Chem. Biodiv. 2004, 1, 1111-1239.

32 G. Lelais, D. Seebach, Biopolymers 2004, 76, 206-243.

33 D. Seebach, T. Kimmerlin, R. Sebesta, M. A. Campo, A. K. Beck, Tetrahedron 2004, 60, 7455-7466.

34 F. Fülop, T. A. Martinek, G. K. Toth, Chem. Soc. Rev. 2006, 35, 323334.

35 D. Seebach, D. F. Hook, A. Glättli, Biopolymers (Pept. Sci) 2006, 84, 2337.

36 J. Kovacs, R. Ballina, R. L. Rodin, D. Balasubramanian, J. Applequist, $J$. Am. Chem. Soc. 1965, 87, 119-120.

37 J. M. Fernández-santín, J. Ayamí, A. Rodríguez-Galán, S. Muñoz-Guerra, J. A. Subirana, Nature, 1984, 311, 5354.
38 H. N. Rydon, J. Chem. Soc. 1964, 1328-1333.

39 H. M. Müller, D. Seebach, Angew. Chem. Int. Ed. Engl. 1993, 32, 477502.

40 D. Seebach, M. G. Fritz, Biol. Macromolecules 1999, 25, 217-236.

41 G. P. Dado, S. H. Gellman, J. Am. Chem. Soc. 1994, 116, 1054-1062.

42 T. Hinterman, D. Seebach, Synlett 1997, 437-438.

43 D. Seebach, P. E. Ciceri, M. Overhand, B. Jaun, D. Rigo, L. Oberer, U. Hommel, R. Amstutz, H. Widmer, Helv. Chim. Acta 1996, 79, 2043-2066.

44 K. Gademann, B. Jaun, D. Seebach, R. Perozzo, L. Scapozza, G. Folkers, Helv. Chim. Acta 1999, 82, 1-11.

45 T. Hintermann, K. Gademann, B. Jaun, D. Seebach, Helv. Chim. Acta 1998, 81, 983-1002.

46 S. Hanessian, X. Luo, R. Schaum, S. Michnick, J. Am. Chem. Soc. 1998, 120, 8569-8570.

47 D. Seebach, M. Brenner, M. Rueping, B. Schweizer, B. Jaun, Chem. Commun. 2001, 207-208.

48 D. Seebach, M. Brenner, M. Rueping, B. Jaun, Chem. Eur. J. 2002, 8, 573584.

49 A. Banerjee, P. Balaram, Curr. Science 1997, 73, 1067-1077.

50 S. Abele, P. Seiler, D. Seebach, Helv. Chim. Acta 1999, 82, 1559-1571.

51 D. Seebach, S. Abele, T. Sifferlen, M. Hänggi, S. Gruner, P. Seiler, Helv. Chim. Acta 1998, 81, 2218-2219.

52 D. Seebach, T. Sifferlen, P. A. Mathieu, A. M. Häne, C. M. Krell, D. J. Bierbaum, S. Abele, Helv. Chim. Acta 2000, 83, 2849-2864.

53 D. Seebach, T. Sifferlen, D. J. Bierbaum, M. Rueping, B. Jaun, B. Schweizer, J. Schaefer, A. K. Mehta, R. D. O'Connor, B. H. Meier, M. Ernst, A. Glättli, Helv. Chim. Acta 2002, 85, 2877-2917.

54 A. Glättli, X. Daura, D. Seebach, W. F. van Gunsteren, J. Am. Chem. Soc. 2002, 124, 12972-12978.

55 D. Seebach, S. Abele, K. Gademann, G. Guichard, T. Hintermann, B. Jaun, J. L. Matthews, J. V. Schreiber, L. 
Oberer, U. Hommel, H. Widmer, Helv. Chim. Acta 1998, 81, 932-982.

56 D. H. Appella, L. A. Christianson, I. L. Karle, D. R. Powell, S. H. Gellman, J. Am. Chem. Soc. 1999, 121, 62066212.

57 J. J. Barchi Jr, X. Huang, D. H. Apella, L. A. Christianson, S. R. Durell, S. Gellman, J. Am. Chem. Soc. 2000, 122, 2711-2718.

58 D. H. Appella, L. A. Christianson, D. A. Klein, D. R. Powell, X. Huang, J. J. Barchi, S. H. Gellman, Nature 1997, 387, 381-384.

59 D. H. Appella, L. A. Christianson, D. A. Klein, M. R. Richards, D. R. Powell, S. H. Gellman, J. Am. Chem. Soc. 1999, 121, 7574-7581.

60 L. A. Christianson, M. J. Lucero, D. H. Appella, D. A. Klein, S. H. Gellman, J. Comput. Chem. 2000, 21, 763-773.

61 T. D. W. Claridge, J. M. Goodman, A. Moreno, D. Angus, S. F. Barker, C. Taillefumier, M. P. Watterson, G. W. J. Fleet, Tetrahedron Lett. 2001, 42, 4251-4255.

62 A. Hetenyi, I. M. Mandity, T. A. Martinek, G. K. Toth, F. Fülöp, J. Am. Chem. Soc. 2005, 127, 547-553.

63 J. D. Winkler, E. L. Piatnitski, J. Mehlmann, J. Kasparec, P. H. Axelsen, Angew. Chem. Int. Ed. 2001, 40, 743-745

64 S. Izquierdo, M. J. Kogan, T. Parella, A. G. Moglioni, V. Branchadell, E. Giralt, R. M. Ortuno, J. Org. Chem. 2004, 69, 5093-5099.

65 S. Chandrasekhar, M. S. Reddy, B. N. Babu, B. Jagadeesh, A. Prabhakar, B. Jagannadh, J. Am. Chem. Soc. 2005, 127, 9664-9665.

66 L. Szabo, B. L. Smith, K. D. McReynolds, A. Parrill, E. R. Morris, J. Gervay, J. Org. Chem. 1998, 63, 1074-1078.

67 M. D. Smith, D. D. Long, T. D. W. Claridge, G. W. J. Fleet, D. G. Marquess, Chem. Commun. 1998, 2039-2040.

68 T. D. W. Claridge, D. D. Long, N. L. Hungerford, R. T. Aplin, M. D. Smith, D. G. Marquess, G. W. J. Fleet Tetrahedron Lett. 1999, 40, 21992202.
69 T. D. W. Claridge, D. D. Long, C. M. Baker, B. Odell, G. H. Grant, A. A. Edwards, G. E. Tranter, G. W. J. Fleet, M. D. Smith, J. Org. Chem. 2005, 70, 2082-2090.

70 C. Baldauf, R. Günther, H.-J. Hofmann, J. Org. Chem. 2004, 69, 6214-6220.

71 R. W. Hoffmann, Angew. Chem. Int. Ed. Engl. 1992, 31, 1124-1134.

72 R. W. Hoffman, Angew. Chem. Int. Ed. 2000, 39, 2054-2070.

73 D. L. Boger, T. M. Ramsey, H. Cai, S. T. Hoehn, J. Stubbe, J. Am. Chem. Soc. 1998, 120, 9149-9158.

74 C. Grison, P. Coutrot, S. Geneve, C. Didierjean, M. Marraud, J. Org. Chem. 2005, 70, 10753-10764.

75 P. G. Vasudev, N. Shamala, K. Ananda, P. Balaram, Angew. Chem. Int. Ed. 2005, 44, 4972-4975.

76 J. Farrera-Sinfreu, L. Zaccaro, D. Vidal, X. Salvatella, E. Giralt, M. Pons, F. Albericio, M. Royo, J. Am. Chem. Soc. 2004, 126, 60486057.

77 V. Semetey, D. Rognan, C. Hemmerlin, R. Graff, J.-P. Briand, M. Marraud, G. Guichard, Angew. Chem. Int. Ed. 2002, 41, 1893-1895.

78 C. Hemmerlin, M. Marraud, D. Rognan, R. Graff, V. Semetey, J. P. Briand, G. Guichard, Helv. Chim. Acta 2002, 85, 3692-3711.

79 A. Violette, M. C. Averlant-Petit, V. Semetey, C. Hemmerlin, R. Casimir, R. Graff, M. Marraud, J.-P. Briand, D. Rognan, G. Guichard, J. Am. Chem. Soc. 2005, 127, 2156-2164.

80 A. Violette, S. Fournel, K. Lamour, O. Chaloin, B. Frisch, J.-P. Briand, H. Monteil, G. Guichard, Chem. Biol. 2006, 13, 531-538.

81 M. Rueping, B. Jaun, D. Seebach, Chem. Commun. 2000, 2267-2268.

82 D. H. Appella, J. J. Barchi Jr, S. R. Durell, S. H. Gellman, J. Am. Chem. Soc. 1999, 121, 2309-2310.

83 M. Schinnerl, J. K. Murray, J. M. Langenhan, S. H. Gellman, Eur. J. Org. Chem. 2003, 721-726.

84 X. Wang, J. F. Espinosa, S. H. Gellman, J. Am. Chem. Soc. 2000, 122, 4821-4822. 
85 E. A. Porter, X. Wang, M. A. Schmitt, S. H. Gellman, Org. Lett. 2002, 4, 3317-3319.

86 M. G. Woll, J. D. Fisk, P. R. LePlae, S. H. Gellman, J. Am. Chem. Soc. 2002, 124, 12447-12452.

87 T. L. Raguse, E. A. Porter, B. Weisblum, S. H. Gellman, J. Am. Chem. Soc. 2002, 124, 12774-12785.

88 P. R. LePlae, J. D. Fisk, E. A. Porter, B. Weisblum, S. H. Gellman, J. Am. Chem. Soc. 2002, 124, 6820-6821.

89 J. S. Park, H.-S. Lee, J. R. Lai, B. M. Kim, S. H. Gellman, J. Am. Chem. Soc. 2003, 125, 8539-8545.

90 P. I. Arvidsson, M. Rueping, D. Seebach, Chem. Commun. 2001, 649650.

91 R. P. Cheng, W. F. DeGrado, J. Am. Chem. Soc. 2001, 123, 5162-5163.

92 T. L. Raguse, J. R. Lai, S. H. Gellman, J. Am. Chem. Soc. 2003, 125, 55925593.

93 T. L. Raguse, J. R. Lai, S. H. Gellman, Helv. Chim. Acta 2002, 85, 41544164.

94 S. A. Hart, A. B. F. Bahadoor, E. E. Matthews, X. J. Qiu, A. Schepartz, J. Am. Chem. Soc. 2003, 125, 40224023.

95 J. A. Kritzer, J. Tirado-Rives, S. A. Hart, J. D. Lear, W. L. Jorgensen, A. Schepartz, J. Am. Chem. Soc. 2005, 127, 167-178.

96 D. A. Guarracino, H. R. Chiang, T. N. Banks, J. D. Lear, M. E. Hodsdon, A. Schepartz, Org. Lett. 2006, 8, 807810.

97 R. P. Cheng, W. F. Degrado, J. Am. Chem. Soc. 2002, 124, 11564-11565.

98 W. F. van Gunsteren, S. R. Billeter, A. A. Eising, P. H. Hünenberger, P. Krüger, A. E. Mark, W. R. P. Scott, I. G. Tironi, Biomolecular Simulation: The GROMOS96 Manual and User Guide; Vdf Hochschulverlag AG an der ETH Zürich: Zürich, Switzerland.

99 X. Daura, K. Gademann, B. Jaun, D. Seebach, W. F. van Gunsteren, A. E. Mark, Angew. Chem. Int. Ed. Engl. 1999, 38, 236-240.

100 X. Daura, W. F. van Gunsteren, D. Rigo, B. Jaun, D. Seebach, Chem. Eur. J. 1997, 3, 1410-1417.
101 X. Daura, B. Jaun, D. Seebach, W. F. van Gunsteren, A. E. Mark, J. Mol. Biol. 1998, 280, 925-932.

102 X. Daura, W. F. van Gunsteren, A. E. Mark, Proteins 1999, 34, 269-280.

103 D. Seebach, J. V. Schreiber, S. Abele, X. Daura, W. F. van Gunsteren, Helv. Chim. Acta 2000, 83, 34-57.

104 W. F. van Gunsteren, R. Burgi, C. Peter, X. Daura, Angew. Chem. Int. Ed. Engl. 2001, 40, 351-355.

105 K. Wright, M. Sarciaux, M. Wakselman, J. P. Mazaleyrat, M. Crisma, F. Formaggio, C. Peggion, A. Toffoletti, C. Corvaja, C. Toniolo, Proc. 19th American Peptide Symposium; Blondelle, S. E., Ed.; American Peptide Society, 2005, 557-558.

106 E. Vass, M. Hollosi, F. Besson, R. Buchet, Chem. Rev. 2003, 103, 1917.

107 M. Crisma, F. Formaggio, A. Moretto, C. Toniolo, Biopolymers (Pept. Sci.) 2006, 84, 3-12.

108 A. I. Jiménez, G. Ballano, C. Cativiela, Angew. Chem. Int. Ed. 2005, 44, 396.

109 K. Gademann, A. Häne, M. Rueping, B. Jaun, D. Seebach, Angew. Chem. Int. Ed. 2003, 42, 1534-1537.

110 R. J. Doerksen, B. Chen, J. Yuan, J. D. Winkler, M. L. Klein, Chem. Commun. 2003, 2534-2535.

111 G. V. M. Sharma, P. Jayaprakash, K. Narsimulu, A. Ravi Sankar, K. Ravinder Reddy, P. Radha Krishna, A. C. Kunwar, Angew. Chem. Int. Ed. 2006, 45, 2944-2947.

112 D. Yang, F. F. Ng, Z. J. Li, Y. D. Wu, K. W. K. Chan, D. P. Wang, J. Am. Chem. Soc. 1996, 118, 9794-9795.

113 Y. D. Wu, D. P. Wang, K. W. K. Chan, D. Yang, J. Am. Chem. Soc. 1999, 121, 11189-11196.

114 C. Peter, X. Daura, W. F. van Gunsteren, J. Am. Chem. Soc. 2000, 122, 7461-7466.

115 D. Yang, J. Qu, B. Li, F. F. Ng, X. C. Wang, K. K. Cheung, D. P. Wang, Y. D. Wu, J. Am. Chem. Soc. 1999, 121, 589-590.

116 D. Yang, J. Qu, W. Li, Y. Ren, D.-P. Wang, Y. D. Wu, J. Am. Chem. Soc. 2003, 125, 14452-14457.

117 D. Yang, Y. H. Zhang, N. Y. Zhu, J. Am. Chem. Soc. 2002, 124, 9966-9967. 
118 D. Yang, Y. H. Zhang, B. Li, D. W. Zhang, J. C. Y. Chan, N. Y. Zhu, S. W. Luo, Y. D. Wu, J. Am. Chem. Soc. 2004, 126, 6956-6967.

119 D. Yang, D. W. Zhang, Y. Hao, Y. D. Wu, S. W. Luo, N. Y. Zhu, Angew. Chem. Int. Ed. 2004, 43, 6719-6722.

120 F. Chen, N. Y. Zhu, D. Yang, J. Am. Chem. Soc. 2004, 126, 15980-15981.

121 R. Günther, H.-J. Hoffmann, J. Am. Chem. Soc. 2001, 123, 247-255.

122 G. Lelais, D. Seebach, Helv. Chim. Acta, 2003, 86, 4152-4168.

123 A. Cheguillaume, A. Salaün, S. Sinbandhit, M. Potel, P. Gall, M. Baudy-Floc'h, P. Le Grel, J. Org. Chem. 2001, 66, 4923-4929.

124 A. Aubry, J. P. Mangeot, J. Vidal, A. Collet, S. Zerkout, M. Maraud, Int. J. Pept. Protein Res. 1994, 43, 305-311.

125 A. Salaün, M. Potel, T. Roisnel, P. Gall, P. Le Grel, J. Org. Chem. 2005, 70, 6499-6502.

126 A. Salaün, A. Favre, B. Le Grel, M. Potel, P. Le Grel, J. Org. Chem. 2006, 71, 150-158.

127 L. Thévenet, R. Vanderesse, M. Marraud, C. Didierjean, A. Aubry, Tetrahedron Lett. 2000, 41, 2361-2364.

128 P. Le Grel, A. Salaün, M. Potel, B. Le Grel, F. Lassagne, J. Org. Chem. 2006 71, 5638-5645.

129 G. N. Ramachandran, R. Chandrasekharan, Indian J. Biochem. Biophys. 1972, 9, 1-11.

130 D. W. Urry, Proc. Natl. Acad. Sci. USA 1971, 68, 672-676.

131 P. De Santis, S. Morosetti, R. Rizzo, Macromolecules 1974, 7, 52-58.

132 E. Benedetti, B. Di Blasio, C. Pedone, G. P. Lorenzi, L. Tomasic, V. Gramlich, Nature 1979, 282, 630.

133 G. P. Lorenzi, H. Jaeckle, L. Tomasic, V. Rizzo, C. Pedone, J. Am. Chem. Soc. 1982, 104, 1728-1733.

134 E. Navarro, R. Tejero, E. Fenude, B. Celda, Biopolymers 2001, 59, 110-119.

135 E. Navarro, E. Fenude, B. Celda, Biopolymers 2004, 73, 229-241.

136 D. A. Langs, Science 1988, 241, 188191.

137 A. L. Lomize, V. Orekhov, A. S. Arseniev, Bioorg. Khim. 1992, 18, 182-200.
138 B. M. Burkhart, N. Li, D. A. Langs, W. A. Pangborn, W. L. Duax, Proc. Natl. Acad. Sci. USA 1998, 95, 12950 12955.

139 F. Kovacs, J. Quine, T. A. Cross, Proc. Natl. Acad. Sci. USA 1999, 96, 79107915.

140 M. D. Yoder, N. T. Keen, F. Jurnak, Science 1993, 260, 1503-1507.

141 C. R. H. Raetz, S. L. Roderick, Science 1995, 270, 997-1000.

142 P. Lengar, N. V. Jishi, P. Balaram, Structure 2006, 14, 529-542.

143 M. F. Perutz, J. L. Finch, J. Berriman, A. Lesk, Proc. Natl. Acad. Sci. USA 2002, 99, 5591-5595.

144 D. Seebach, K. Gademann, J. V. Schreiber, J. L. Matthews, T. Hintermann, B. Jaun, L. Oberer, U. Hommel, H. Widmer, Helv. Chim. Acta 1997, 80, 2033-2038.

145 M. Rueping, J. V. Schreiber, G. Lelais, B. Jaun, D. Seebach, Helv. Chim. Acta 2002, 85, 2577-2593.

146 S. A. Gruner, V. Truffault, G. Voll, E. Locardi, M. Stockle, H. Kessler, Chem. Eur. J. 2002, 8, 4365-4376.

147 G. V. M. Sharma, K. R. Reddy, P. R. Krishna, A. R. Sankar, K. Narsimulu, S. K. Kumar, P. Jayaprakash, B. Jagannadh, A. C. Kunwar, J. Am. Chem. Soc. 2003, 125, 1367013671.

148 G. V. M. Sharma, K. R. Reddy, P. R. Krishna, A. R. Sankar, P. Jayaprakash, B. Jagannadh, A. C. Kunwar, Angew. Chem. Int. Ed. Engl. 2004, 43, 39613965.

149 R. Baron, D. Bakowies, W. F. van Gunsteren, X. Daura, Helv. Chim. Acta, 2002, 85, 3872-3882.

150 D. Trzesniak, A. Glattli, B. Jaun, W. F. van Gunsteren, J. Am. Chem. Soc. 2005, 127, 14320-14329.

151 P. J. Gee, W. F. van Gunsteren, Proteins 2006, 63, 136-143.

152 Y. D. Wu, D. P. Wang, J. Am. Chem. Soc. 1999, 121, 9352-9362.

153 C. Baldauf, R. Günther, H.-J. Hofmann, Angew. Chem. Int. Ed. 2004, 43, 1594-1597.

154 C. Baldauf, R. Günther, H.-J. Hofmann, Biopolymers 2005, 80, 675687. 
155 C. Baldauf, R. Günther, H.-J. Hofmann, Biopolymers 2006, 84, 408413.

156 C. Baldauf, R. Günther, H.-J. Hofmann, J. Org. Chem. 2006, 71, 1200-1208.

157 G. V. M. Sharma, P. Nagendar, P. Jayaprakash, P. Ragha Krishna, K. V. S. Ramakrishna, A. C. Kunwar, Angew. Chem. Int. Ed. Engl. 2005, 44, 5878-5882.

158 S. Krauthauser, L. A. Christianson, D. R. Powell, and S. H. Gellman, J. Am. Chem. Soc. 1997, 119, 1171911720.

159 D. Seebach, S. Abele, K. Gademann, B. Jaun, Angew. Chem. Int. 1999, 38, 1595-1597.

160 M. Hagihara, N. J. Anthony, T. J. Stout, J. Clardy, S. L. Schreiber, J. Am. Chem. Soc. 1992, 114, 65686570.

161 M. G. Woll, J. R. Lai, I. A. Guzei, S. J. C. Taylor, M. E. B. Smith, S. H. Gellman, J. Am. Chem. Soc. 2001, 123, 11077-11078.

162 Y. J. Chung, B. R. Huck, L. A. Christianson, H. E. Stanger, S. Krauthauser, D. R. Powell, S. H. Gellman, J. Am. Chem. Soc. 2000, 122, 3995-4004.

163 Y. J. Chung, L. A. Christianson, H. E. Stanger, D. R. Powell, S. H. Gellman, J. Am. Chem. Soc. 1998, 120, 1055510556.

164 X. Daura, K. Gademann, H. Schäfer, B. Jaun, D. Seebach, W. F. van Gunsteren, J. Am. Chem. Soc. 2001, 123, 2393-2404.

165 S. Hanessian, X. Luo, R. Schaum, Tetrahedron Lett. 1999, 40, 49254929.

166 M. Brenner, D. Seebach, Helv. Chim. Acta 2001, 84, 2155-2166.

167 S. De Pol, C. Zorn, C. D. Klein, O. Zerbe, O. Reiser, Angew. Chem. Int. Ed. Engl. 2004, 43, 511-514.

168 A. Hayen, M. A. Schmitt, F. N. Ngassa, K. A. Thomasson, S. H. Gellman, Angew. Chem. Int. Ed. 2004, 43, 505-510.

169 M. A. Schmitt, B. Weisblum, S. H. Gellman, J. Am. Chem. Soc. 2004, 126, 6848-6849.
170 M. A. Schmitt, S. H. Choi, I. A. Guzei, S. H. Gellman, J. Am. Chem. Soc. 2005, 127, 13130-13131.

171 M. A. Schmitt, S. H. Choi, I. A. Guzei, S. H. Gellman, J. Am. Chem. Soc. 2006, 128, 4538-4539.

172 K. Ananda, P. G. Vasudev, A. Sengupta, K. M. Poopathi Raja, N. Shamala, P. Balaram, J. Am. Chem. Soc. 2005, 127, 16668-16674.

173 R. S. Roy, P. Balaram, J. Pept. Res. 2004, 63, 279-289.

174 I. L. Karle, A. Pramanik, A. Banerjee, S. Bhattacharjya, P. Balaram, J. Am. Chem. Soc. 1997, 119, 9087-9095.

175 R. S. Roy, I. L. Karle, S. Raghothama, P. Balaram, Proc. Natl. Acad. Sci. USA 2004, 101, 16478-16482.

176 T. S. Haque, J. C. Little, S. H. Gellman, J. Am. Chem. Soc. 1994, 116, 4105-4106.

177 M. Ramirez-Alvarado, F. J. Blanco, L. Serrano, Nat. Struct. Biol. 1996, 3, 604-612.

178 I. L. Karle, S. K. Awasthi, P. Balaram, Proc. Natl. Acad. Sci. USA 1996, 93, 8189-8193.

179 I. Karle, H. N. Gopi, P. Balaram, Proc. Natl. Acad. Sci. USA 2002, 99, 5160-5164.

180 I. L. Karle, H. N. Gopi, P. Balaram, Proc. Natl. Acad. Sci. USA 2001, 98, 3716-3719.

181 H. N. Gopi, R. S. Roy, S. Raghothama, I. Karle, P. Balaram, Helv. Chim. Acta 2002, 85, 33133330.

182 R. S. Roy, H. N. Gopi, S. Raghothama, I. L. Karle, P. Balaram, Chem. Eur. J. 2006, 12, 3295-3302.

183 J. M. Langenhan, I. A. Guzei, S. H. Gellman, Angew. Chem. Int. Ed. 2003, 42, 2402-2405.

184 B. R. Huck, J. D. Fisk, S. H. Gellman, Org. Lett. 2000, 2, 2607-2610.

185 C. A. Hunter, A. Spitaleri, S. Tomas, Chem Commun. 2005, 3691-3693.

186 C. A. Hunter, M. J. Packer, Chem. Eur. J. 1999, 5, 1891-1897.

187 A. P. Bisson, F. J. Carver, D. S. Eggleston, R. C. Haltiwanger, C. A. Hunter, D. L. Livingstone, J. F. 
McCabe, C. Rotger, A. E. Rowan, J. Am. Chem. Soc. 2000, 122, 88568868.

188 C. A. Hunter, J. Am. Chem. Soc. 1992, 114, 5303-5311.
189 O. Lukin, F. Vögtle, Angew. Chem. Int. Ed. 2005, 44, 1456-1477.

190 O. Safarowsky, M. Nieger, R. Fröhlich, F. Vögtle, Angew. Chem. Int. Ed. 2000, 39, 1616-1618. 